SERI/TR-255-1828

UC Category: 62e

DE85008779

\title{
Materials Research for Passive Solar Systems: Solid-State Phase-Change Materials
}

\author{
D. K. Benson \\ J. D. Webb \\ R. W. Burrows \\ J. D. O. McFadden \\ C. Christensen
}

March 1985

Prepared under Task Nos. 1275.00 and 1464.00

WPA No. 304

\section{Solar Energy Research Institute}

A Division of Midwest Research Institute

1617 Cole Boulevard

Golden, Colorado 80401

Prepared for the

U.S. Department of Energy

Contract No. EG-77-C-01-4042 


\section{PREFACE}

This report documents research progress during FY 1982 on a class of solid-to-solid phase-change materials. These hydrocarbon molecular crystals were evaluated for possible use as thermal energy storage media in passive solar architectural applications. The research was supported by the U.S. Department of Energy, Office of Conservation and Solar Energy, Passive and Hybrid Systems Branch.

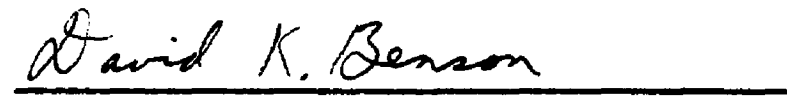

David K. Benson

Approved for

SOLAR ENERGY RESEARCH INSTITUTE

Gordon E. Gross, P.E., Manager

Materials Research Branch

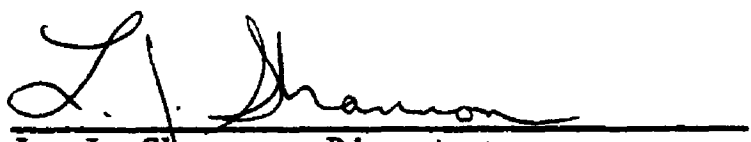

L. J. Shannon, Director

Solar Reat Research Division 


\section{SURMARY}

\section{Objectives}

The objectives of our research are to evaluate the technical and economic feasibility of using solid-state phase-change materials for thermal energy storage in passive solar architectural applications and to develop a better understanding of the molecular processes involved in solid-state transformations.

\section{Discussion}

The temporary storage of solar energy is an essential component of any passive solar heating strategy. Ordinarily such storage is accomplished by the use of massive construction materials such as adobe, concrete, or brick or with the use of water in specially designed storage tanks. Such materials store heat over the entire range of their operating temperatures with a continuous change in temperature as the stored thermal energy content changes. These materials are storing "sensible heat" since their changing state of energy storage can be readily sensed as a changing temperature. Specially designed storage materials called phase-change materials undergo reversible physical/chemical changes while absorbing large amounts of thermal energy over narrow temperature ranges. Phase-change materials combine both sensible and phase-change energy storage; consequently they store much larger amounts of energy per unit mass than the simpler, sensible thermal storage materials. Typical phasechange materials are waxes or salt hydrates (i.e., sodium sulfate decahydrate and calcium chloride hexahydrate), which absorb thermal energy upon melting and subsequently release the same amount of energy upon solidification.

The research reported here focuses on a different type of phase-change material--a class of materials that reversibly absorb large amounts of thermal energy during solid-state transformations. These solid-state phase-change materials offer the advantage of storing large amounts of energy per unit mass without the disadvantages of melting and the attendant concerns over leakage of the phase-change material.

The solid-state phase-change materials that are the focus of this research are crystalline solid hydrocarbons belonging to the class of compounds called polyalcohols (or polyols). They are similar in molecular structure, having a five carbon atom core and between zero and four hydroxyl ( $-\mathrm{OH}$ ) groups attached to the outer four carbon atoms. The three compounds from this group having the most practical potential are pentaerythritol $\left[\mathrm{C}-\left(\mathrm{CH}_{2} \mathrm{OH}\right)_{4}\right]$, pentaglycerine $\left[\mathrm{CH}_{3}-\mathrm{C}-\left(\mathrm{CH}_{2} \mathrm{OH}\right)_{3}\right]$, and neopentyl-glycol $\left[\left(\mathrm{CH}_{3}\right)_{2}-\mathrm{C}-\left(\mathrm{CH}_{2} \mathrm{OH}\right)_{2}\right]$. These three compounds absorb between 126 and $293 \mathrm{~kJ} / \mathrm{kg}$. (30 and $70 \mathrm{cal} / \mathrm{g}$ ) during solid-state transformations at temperatures between $53^{\circ}$ and $188^{\circ} \mathrm{C}\left(70^{\circ}\right.$ to $100^{\circ} \mathrm{C}$ below their melting temperatures).

Binary mixtures of these compounds when melted together form stable solid solutions that also exhibit solid-state transformations. Our binary solid solutions store between 84 and $293 \mathrm{~kJ} / \mathrm{kg}(20$ and $70 \mathrm{cal} / \mathrm{g}$ ) at transformation temperatures between $25^{\circ}$ and $188^{\circ} \mathrm{C}$; the transformation temperature may be 
selected over this range merely by choosing the appropriate proportions for the binary solid solution.

By using differential thermal analysis, we measured a number of the most relevant thermophysical properties of 20 of these solid solutions. These measurements included transformation and melting temperatures, enthalpies, and specific heats.

We made a preliminary examination of the kinetics of solid-state transformations. A large degree of undercooling was observed, particularly at higher rates of cooling $\left(0.33^{\circ} \mathrm{C} \mathrm{s}^{-1}\right)$. Our search for a nucleating agent that would reduce the degree of undercooling was successful: powdered graphite added as a particulate dispersant $(0.1 \mathrm{wt} \%)$ reduced the amount of undercooling by at least $50 \%$ in pentaglycerine.

We also studied the cyclic stability of the solid-solution phase-change materials. A binary solid solution of 12.5 mol \% neopentyl-glycol in pentaglycerine was cycled through its solid-state transformation 732 times with no significant loss in storage capacity nor change in transformation temperature.

Infrared spectroscopy was used to observe changes in the molecular interactions that occur as a result of the solid-state transformation. Changes in the infrared absorption peak associated with the vibrational stretching mode of the $\mathrm{OH}$ groups were characteristic of hydrogen resonance bonds being reversibly broken at the transformation temperature. We developed a conceptual model for the transformation based on nearest neighbor intermolecular hydrogen bonding. This model appears to be consistent with the available thermodynamic data.

Computer simulations were initiated to estimate the probable performance of solid-state phase-change materials in subsystems of passive solar architecture such as Trombe walls. These studies were based on a single thermal zone simulation of a SERI experimental house (1200 $\mathrm{ft}^{2}$ of floor space) with and without a hypothetical south-facing Trombe wall (200 $\mathrm{ft}^{2}$ of wall area). The performance of the house was judged by its estimated annual heating requirements as determined from annual summaries of hour-by-hour computer simulations. We performed parametric simulations in which the solid-state phasechange material transformation temperature, the wall thickness, and the wall thermal diffusivity were varied. The solid-state phase-change material wall was also compared to a simulated concrete Trombe wall.

\section{Conclusions}

The tentative results from the simulations helped to guide the laboratory research. For example, a solid-state phase-change material transformation temperature of $\sim 27^{\circ} \mathrm{C}$ was shown to be optimum for this Trombe wall. An increase in thermal diffusivity of the material by a factor of five was predicted to improve the performance by $30 \%$. The laboratory thermal analyses identified suitable binary solid solutions with transformation temperatures near $27^{\circ} \mathrm{C}$. Our calculations suggest that their thermal diffusivities can be increased fivefold by minor additions ( 2 wt \%) of graphite or similarly conductive materials. 
The computer simulations also indicated that a solid-state phase-change material Trombe wall could perform as well as a concrete Trombe wall that is four times thicker and nine times heavier. These comparisons suggest that the solid-state phase-change materials may offer significant design advantages in applications where massive structures are impractical, such as retrofits to existing buildings and in modular passive solar buildings.

Preliminary estimates of the cost of a solid-state phase-change material Trombe wall suggest that it would cost nearly twice as much as a concrete Trombe wall with comparable performance. Either the design advantages of lowmass Trombe walls will have to be sufficient to offset this cost difference or the performance of the solid-state phase-change materials will have to be improved before they become economical. Such improvements may take the form of new solid-solution mixtures with higher enthalpies of transformation, new chemical analogues of the polyols with higher enthalpies of transformation, or new composite formulations with much higher thermal conductivities.

Research is continuing in an effort to

- Understand the solid-state phase-change material transformation mechanisms

- Improve the performance of the materials

- Evaluate other potential passive solar applications for solid-state phase-change materials. 


\section{TABLE OP CONTENTS}

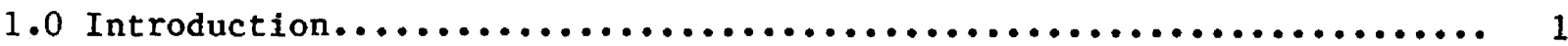

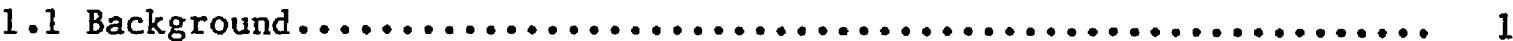

1.2 objective..........................................4

1.3 Approach..........................................4

1.3.1 Engineering Thermophysical Properties................ 4

1.3 .2 Computer Modeling............................... 6

1.3.3 Mechanisms of the Solid-State Transformations ........... 6

1.4 Solid-State Phase-Change Materials Selected for Analysis........ 6

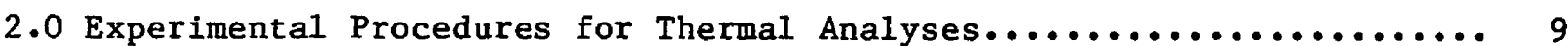

3.0 Results............................................. 12

3.1 Thermophysical Properties.............................. 12

3.2 Undercooling of the Solid-State Transformation.............. 12

3.3 Nucleation of the Solid-State Transformation................ 22

3.4 Infrared Spectroscopy ................................. 22

3.5 A Nearest-Neighbor Interaction Model...................... 27

3.6 Systems Analyses of, Solid-State Phase-Change Material Use

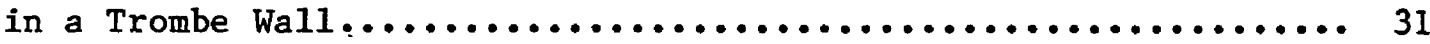
3.6.1 Computer Modeling of a Trombe Wall Performance.......... 31 3.6 .2 Economic Feasibility............................ 31

4.0 Conclusions and Recommendations.......................... 37

5.0 References........................................... 38

Appendix............................................... 42 


\section{LIST OF FIGURES}

Page

1-1 Typical Applications for Thermal Energy Storage (TES) Materials in Passive Solar Buildings................................. 2

1-2 Structural Formulas for Three Polyols...................... 8

2-1 Typical Recording of Thermal Power Absorbed by a Solid-State PhaseChange Material as its Temperature Increases....................

2-2 Typical Recordings for Measuring the Specific Heat of a Solid-State Phase-Change Material by Differential Scanning Calorimetry.........

3-1 Differential Scanning Calorimetry Recordings of Solid Solution Mixtures of $P G$ and $N P G . \ldots \ldots \ldots \ldots \ldots \ldots \ldots \ldots \ldots \ldots \ldots \ldots \ldots \ldots \ldots \ldots \ldots \ldots \ldots . . \ldots 14$

3-2 Differential Scanning Calorimetry of Solid Solutions of PE in PG... 14

3-3 Measured Enthalpies and Temperatures of Solid-State Transformation for Mixtures of PG in NPG................................ 15

3-4 Entropies of Transformation for Solid-Solution Mixtures of PG in NPG.

3-5 Summary of the Measured Molar Enthalpies of Transformation in Solid-Solution Mixtures of PE in PG, PE in NPG, and PG in NPG..... 17

3-6 Measured Specific Heats of PG, PE, and a 50\%-50\% Molar Solid Solution..............................................

3-7 Measured Specific Heats of Mixtures of PG and NPG.............. 18

3-8 Differential Scanning Calorimetry Recordings of the Thermal Absorption Peak in an 87.5 mol \% Solution of PG in NPG.......... 18

3-9 Differential Scanning Calorimetry Recordings of the Thermal Absorption and Thermal Energy Release from PG at Different Heating and Cooling Rates................................

3-10 Effect of 0.1 wt \% Addition of Powdered Graphite on the Undercooling of $\mathrm{PG} . \ldots \ldots \ldots \ldots \ldots \ldots \ldots \ldots \ldots \ldots \ldots \ldots \ldots \ldots \ldots \ldots \ldots \ldots$

3-11 Arrhenius Plots of the Reaction Rate Constants for Solid-State Transformations in PG....................................

3-12 Cross Section of a Controlled Temperature Sample Holder for IR Spectroscopy of Solid-State Phase-Change Materials.............. 25

3-13 Infrared Absorbance Spectra of PG.......................... 26 
LIST OF FIGURES (Concluded)

Page

3-14 Infrared Absorbance Spectra of PE........................ 26

3-15 OH Absorption Band Peak Shift as a Function of Temperature in PE... 27

3-16 Gibbs Free Energy vs. Temperature for a First-Order Phase-Change from $\alpha$ to $\beta$ at $\mathrm{T}$..................................... 28

3-17 Measured and Calculated Enthalpies of Transformation in the Homologous Series of PE-Related Polyols...................... 30

3-18 Solar Savings Fraction as a Function of the Solid-State Transformation Temperature in a Phase-Change Material Filled Trombe Wall..................................... 33

3-19 Solar Saving Fraction as a Function of Therma1 Conductivity Assumed for a Solid-State Phase-Change Material................. 33

3-20 Solar Savings Fraction as a Function of Trombe Wall Thickness for Both Solid-State Phase-Change Materials and Concrete.............. 34 


\section{LIST OF TABLES}

Page

1-1 Comparison of Phase-Change Thermal Energy Storage Materials....... 3

1-2 Transition and Fusion Enthalpy and Entropy Data for Various Tetrahedral Substances................................. 5

1-3 Published Thermal Properties of Pentaerythritol and Homologous Compounds Exhibiting Solid-Solid Phase Transitions.............. 7

3-1 Summary of Thermal Properties of Polyol Solid Solutions........... 13

3-2 Materials Tested for Nucleation of Solid-State Phase-Change Material Transformation................................... 23

3-3 Hydroxy1 Absorption Band Peak............................ 27

3-4 Building Characteristics and Assumptions................... 32

3-5 Trombe Wall Characteristics and Assumptions................. 32

3-6 Estimated Costs for Masonry and Phase-Change Material Trombe Walls........................................... 35

A-1 Lethal Dosage Levels of Pentaerythritol for Laboratory Animals..... 40

A-2 Lethal Dosage Levels of Neopentyl-Glycol for Laboratory Anima1s.... 41 
SECTION 1.0

INTRODUCTION

The thermal energy storage materials described in this report are unusual in two respects. They reversibly absorb large amounts of thermal energy during a solid-state transformation well below their melting temperatures, and they can be mixed together to form solid solutions with transition temperatures (selectable by composition) between $25^{\circ} \mathrm{C}$ and $188^{\circ} \mathrm{C}$.

This report summarizes ongoing, exploratory research designed to determine whether use of these unusual solid-state phase-change materials is technically and economically feasible in passive solar thermal energy storage systems.

\subsection{BACKGROUND}

Thermal energy storage is a critical component in passive solar design strategies. With a wel1-designed thermal storage subsystem, the solar heat collected during a portion of the day can heat a building throughout the remainder of the day. In passive solar systems, the heat is generally collected at temperatures well below $100^{\circ} \mathrm{C}$, and storing large amounts of this low-grade thermal energy as sensible heat requires a large mass of storage material. Figure 1-1 illustrates the use of such storage in a building. Traditionally, massive masonry, concrete, or adobe walls were used for thermal energy storage. Large volumes of water in specially designed water walls or storage tanks have also been used. However, in some forms of solar construction, such as modular solar homes or in retrofit applications of solar systems to existing buildings, the space and foundation support required for massive solar thermal storage make it impractical.

The use of phase-change materials can dramatically decrease the mass of material required for solar thermal storage. A phase-change material absorbs and later releases large amounts of energy at the phase-transformation temperature. The most commonly used phase-change material is water, which absorbs $335 \mathrm{~kJ} / \mathrm{kg}(80 \mathrm{cal} / \mathrm{g})$ at the $0^{\circ} \mathrm{C}$ ice/water phase change.

Phase-change thermal storage materials with transformation temperatures more appropriate for storing solar heat have been developed and are now marketed commercially. Table 1-1 summarizes some of these materials as well as the developmental phase-change materials used in our study. All of the phasechange materials developed are like water in that they undergo a transition from solid to liquid when heated and release the latent heat of melting when they once again solidify. These materials are either paraffins (mixtures of aliphatic hydrocarbon by-products of crude oil refining) that melt and solidify with high latent heat, or they are salt hydrates that melt and become water solutions from which the original salt hydrate recrystallizes upon cooling.

Severa1 problems have plagued the development of phase-change thermal storage materials. One set of problems is associated with the containers that must be 


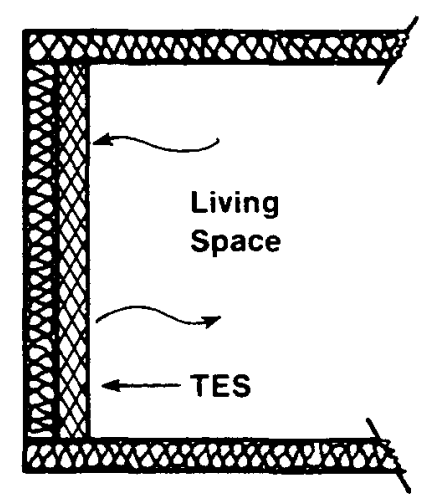

A. Comfort Range Control

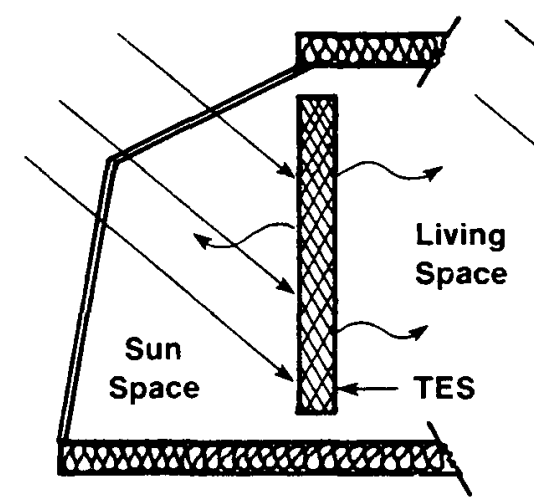

B. Sun Space

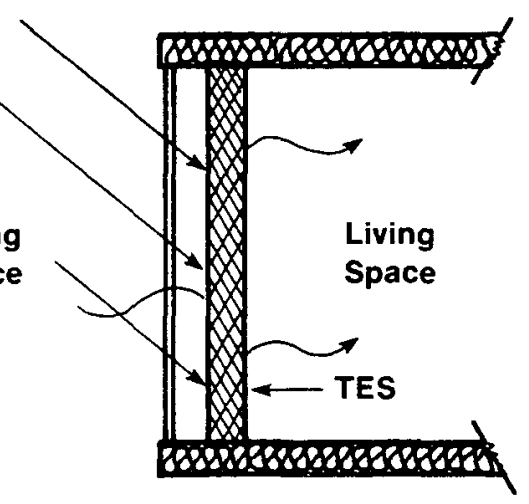

C. Trombe Wall

\section{Figure 1-1. Typical Applications for Thermal Energy Storage (TES) Materials in Passive Solar Buildings}

used for the storage material. In the case of the salt hydrate storage materials, the container problem is aggravated because the material must be isolated from the atmosphere to prevent uptake (or loss) of water and consequent change in composition and loss of efficiency. Low-cost metal containers have not worked well because the salt solutions are corrosive; polymer containers have not worked well because the repeated crystallization of the salt has a tendency to wedge apart seams, much as freezing water causes cracks in rock. Another problem with salt hydrates is their tendency to form partially hydrated or otherwise less soluble crystals that can no longer contribute to the reversible storage process. Commercial salt hydrate storage materials have nucleating agents added to minimize the latter effect, but under some circumstances the nucleating agent becomes segregated and ceases to function.

The paraffins exhibit fewer problems. They require a container that should be sealed to prevent long-term vaporization of the paraffins, but they are not corrosive and show no tendency to destroy seams. Their main limitations are their tendency to remain liquid at temperatures well below the normal melting temperature (called undercooling), and their low thermal conductivities, which limit the rate at which heat can be absorbed and released.

Developmenta1, form-stabilized polymers melt but retain their form. By chemically or radiatively cross-linking polyethylene, the liquid polymer can be made so viscous that it does not deform under its own weight or even under moderate loads. Additional research is required to eliminate the gradual loss of latent heat that occurs during repeated phase-change cycles. These materials have great promise because of minimal container requirements, potential low cost, noncorrosiveness, and nontoxicity. However, it may not be possible 
Table 1 1. Comparison of Phase-Change Thermal Energy Storage Materials

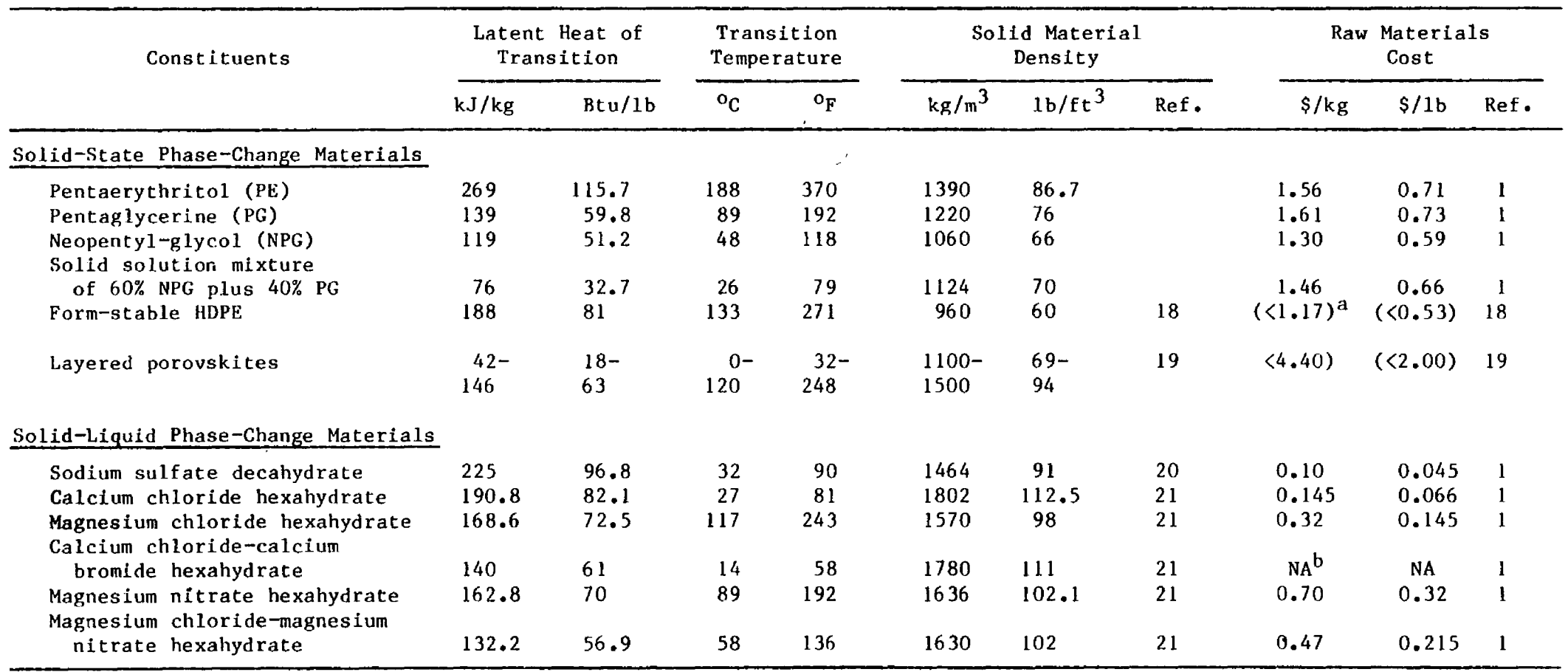

a parentheses indicate a projected cost estimate from the reference cited.

bot available. 
to achieve the needed thermal energy storage performance at temperatures much lower than the $130^{\circ} \mathrm{C}$ already achieved.

The organic solid-state phase-change materials that we are studying for possible passive solar applications were first considered for use in the passive temperature control of satellites. Under NASA sponsorship, a large number of solid-state phase-change materials were evaluated ten years ago [2] (see Table 1-2). At SERI, we have extended the NASA research and discovered organic solid-solutions that lower the useful temperature range of solid-state phase-change materials into the realm of interest to designers of passive solar systems.

\subsection{OBJECTIVE}

The objective of the research described in this report is to evaluate the technical and economic feasibility of using certain solid-state phase-change materials in thermal energy storage subsystems for passive and hybrid solar systems. The research is exploratory in nature because relatively little is known about the materials involved or the physical mechanisms of the solidstate phase-change transformations. For this same reason, economic feasibility mist be judged on a tentative basis until a much more thorough understanding of the materials is developed.

\subsection{APPROACH}

Three parallel efforts constitute our research: the measurement of engineering thermophysical properties of selected solid-state phase-change materials; the modeling of their probable performance in passive solar thermal energy storage systems; and experiments aimed at clarifying the physical mechanisms of the solid-state transformation process.

\subsubsection{Engineering Thermophysical Properties}

The important thermophysical properties in this feasibility study are thermal storage characteristics, including latent heat of transformation and the kinetics of transformation; thermal cycling stability; specific heat for the temperature range of the application; thermal expansion; thermal conductivity; and vapor pressure.

Differential thermal analysis was used to measure the heat of transformation as well as the kinetics of transformation and specific heat for a number of candidate solid-solution mixtures of phase-change materials. Experiments to determine thermal expansion were initiated. A density-gradient column was set up to measure densities of solid-solution phase-change material alloys at room temperature. These density measurements can be combined with thermal expansion measurements to determine density as a function of temperature. A special heat flux calorimeter built at SERI will be used to measure the thermal conductivity of phase-change materials over a range of temperatures. Thermal gravimetric analyses will be used to measure the vapor pressure of selected solid-solution mixtures. 
Table 1-2. Transition and Fusion Enthalpy and Entropy Data for Various Tetrahedral Substances

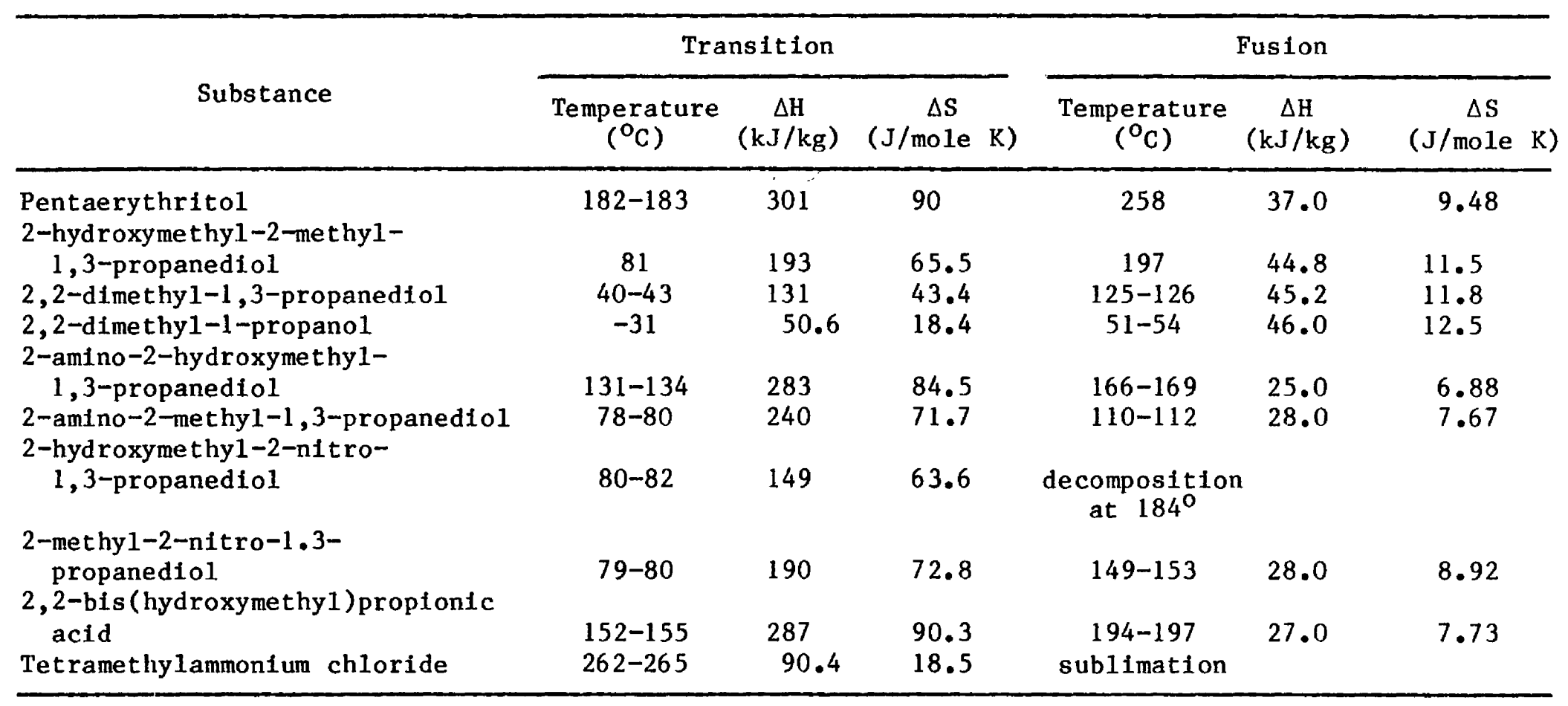

Source: Ref. 3. 
TR-1828

\subsubsection{Computer Modeling}

The computer modeling of phase-change material performance in passive solar thermal energy storage subsystems has two purposes.. The primary purpose is to provide guidance to the research by developing performance models and using them to generate parametric performance curves from which optimal properties for phase-change materials can be inferred. Answers are generated to questions such as: What is the optimum transition temperature for a solid-state phase-change material used in a Trombe wall? What is the benefit of a higher or lower thermal conductivity? What effect does undercooling have on performance? And should undercooling be minimized, or is it beneficial? Answers to these questions guide the research.

Computer modeling can also provide preliminary indications of the economic feasibility of solid-state phase-change materials. For example, the models can predict the amount of fuel to be saved by use of a solid-state phasechange wall of certain dimensions in a representative building. From this result, preliminary cost/ benefit ratios can be determined. Similarly, the increase in cost/benefit ratio to be expected from some change in material property can be used to judge the merits of further corresponding research.

The SERI computer simulations used a thermal network model of the SERI Retrofit House with a Trombe wall added to the model. The Retrofit House has undergone extensive Class $A^{*}$ performance monitoring to validate computer codes. Performance was estimated in terms of the annual solar savings fraction.**

\subsubsection{Mechanisus of the Solid-State Transformations}

We used infrared spectroscopy to study the mechanisms of the solid-state transformations. A special sample holder was used at a controlled temperature to permit measurement of the infrared spectra of the phase-change materials below and above the transition temperatures. Spectral changes occurring reversibly at the transition temperature provide clues to the molecular rearrangements or lattice coordination changes responsible for the reversible energy absorption.

\subsection{SOLID-STATE PHASE-CHANGE MATERIALS SELECTED FOR ANALYSIS}

The solid-state phase-change materials included in this study are simple organic compounds used in large quantities as chemical feedstocks in the resins and munitions industries. Table 1-3 lists some of the characteristics of the compounds that are the focus of this work. A11 are closely related

*Class A performance monitoring involves extensive measurement of temperatures, heat fluxes, air infiltration rates, etc. throughout the building over a range of weather conditions.

**The solar savings fraction is that fraction of the heating energy supplied by the solar installation. 
Table 1-3. Published Thermal Properties of Pentaerythritol and Homologous Compounds Exhibiting Solfd-Solid Phase Transitions

\begin{tabular}{|c|c|c|c|c|c|c|c|c|c|c|c|c|}
\hline \multirow{2}{*}{ Name } & \multirow{2}{*}{ Formula } & \multirow{2}{*}{$\begin{array}{l}\text { Molecular } \\
\text { Weight }\end{array}$} & \multicolumn{2}{|c|}{$\begin{array}{l}\text { Latent Heat } \\
\text { of Melting }\end{array}$} & \multicolumn{2}{|c|}{$\begin{array}{c}\text { Melting } \\
\text { Temperature }\end{array}$} & \multirow{2}{*}{$\begin{array}{l}\text { Entropy of } \\
\text { Melting } \\
(\mathrm{J} / \mathrm{mol} \mathrm{K})\end{array}$} & \multicolumn{2}{|c|}{$\begin{array}{l}\text { Latent Heat } \\
\text { of Transition }\end{array}$} & \multicolumn{2}{|c|}{$\begin{array}{l}\text { Transition } \\
\text { Temperature }\end{array}$} & \multirow{2}{*}{$\begin{array}{c}\text { Entropy of } \\
\text { Transition } \\
\text { (J/mol K) }\end{array}$} \\
\hline & & & $(\mathrm{kJ} / \mathrm{mol})$ & $(\mathrm{cal} / \mathrm{g})$ & $(K)$ & $\left({ }^{\circ} \mathrm{C}\right)$ & & $(\mathrm{kJ} / \mathrm{mol})$ & $(\mathrm{cal} / \mathrm{g})$ & $(\mathrm{K})$ & $\left({ }^{\circ} \mathrm{C}\right)$ & \\
\hline $\begin{array}{l}\text { Pentaerythritol } \\
{[2,2 \text {-B1s }} \\
\text { (hydroxymethyl)- } \\
1,3 \text { propanediol) }\end{array}$ & $\mathrm{C}_{5} \mathrm{H}_{12} \mathrm{O}_{4}$ & 136.15 & 5.01 & 8.80 & $531-533$ & $258-260$ & 9.48 & 41.29 & 72.48 & $457-458$ & $184-185$ & 90 \\
\hline $\begin{array}{l}\text { Pentag lycerine } \\
\text { (2-hydroxymet hyl- } \\
2 \text {-methy } 1-1,3- \\
\text { propaned } 101 \text { ) }\end{array}$ & $\mathrm{C}_{5} \mathrm{H}_{12} \mathrm{O}_{3}$ & 120.15 & 5.36 & 10.67 & $470-471$ & $197-198$ & 11.5 & 23.13 & 46.02 & 354 & 81 & 65.5 \\
\hline $\begin{array}{l}\text { Neopentyl glycol } \\
(2,2-\text { dimethyl- } \\
\text { 1,3-propanediol) }\end{array}$ & $\mathrm{C}_{5} \mathrm{H}_{12} \mathrm{O}_{2}$ & 104.15 & 4.72 & 10.82 & $398-399$ & $125-126$ & 11.8 & 13.64 & 31.30 & $313-316$ & $40-43$ & 43.4 \\
\hline $\begin{array}{l}\text { Neopentyl alcohol } \\
(2,2-\text { dimethyl- } \\
1 \text {-propanol })\end{array}$ & $\mathrm{C}_{5} \mathrm{H}_{12} \mathrm{O}$ & 88.15 & 4.06 & 11.02 & $324-328$ & $51-55$ & 12.5 & 4.70 & 12.74 & 242 & -31 & 18.4 \\
\hline $\begin{array}{l}\text { Neopentane } \\
\text { (2,2-dimethyl- } \\
\text { propane) }\end{array}$ & $\mathrm{C}_{5} \mathrm{H}_{12}$ & 72.15 & 3.26 & 10.79 & 256.61 & -16.54 & 12.7 & 2.59 & 8.6 & 140 & -133 & 18.5 \\
\hline
\end{tabular}


members of a homologous series of polyols, and all have a central carbon atom with four attached carbons forming a tetrahedron.

Figure 1-2 shows the structural formulas for the three compounds of primary interest. Each of these compounds form solid solutions with the others; these solid solutions retain the solid-state transformation characteristics of the parent compounds, but with intermediate heats of transformation and different transition temperatures.

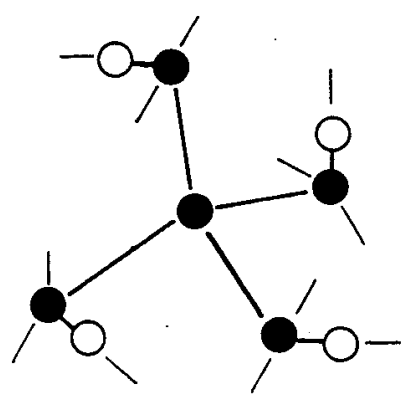

PE

Pentaerythritol

$\mathrm{C}_{5} \mathrm{H}_{12} \mathrm{O}_{4}$

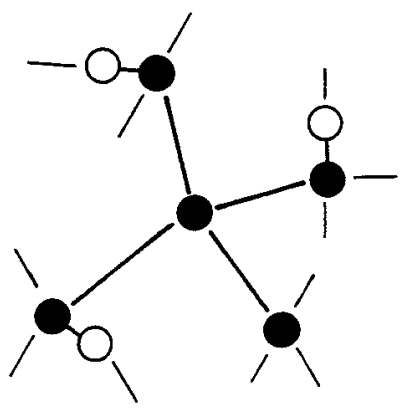

PG

Pentaglycerine

$\mathrm{C}_{5} \mathrm{H}_{12} \mathrm{O}_{3}$

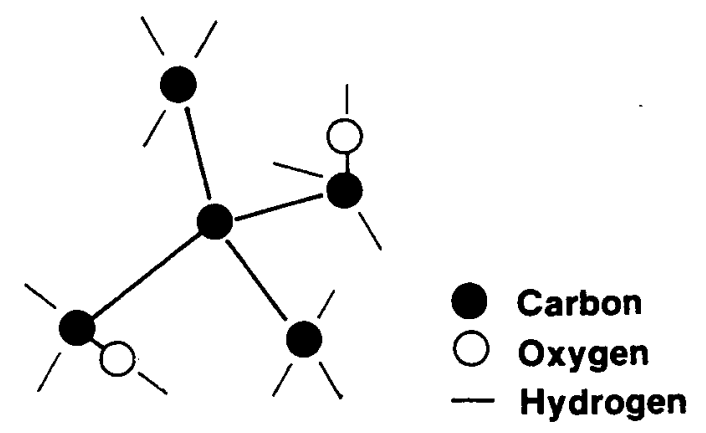

NPG

Neopentyl Glycol

$\mathrm{C}_{5} \mathrm{H}_{12} \mathrm{O}_{2}$

Figure 1-2. Structural Formulas for Three Polyols. (All are tetrahedral molecules with two to four hydroxyl groups attached at the vertices of the tetrahedron.) 
SECTION 2.0

\section{EXPERIMiENTAL PROCEDURES FOR THERMAL ANALYSES}

Differential scanning calorimetry was used to measure thermal characteristics of the pure compounds and their solid solutions. A Perkin-Elmer DSC-2 instrument with microprocessor control and data acquisition interface (Perkin-E1mer TADS unit) was used. This instrumentation and the procedures used in these experiments are known to provide measurements with the following precision: $\pm 0.1 \mathrm{~K}$ in temperature, $\pm 4 \%$ in enthalpy, and $\pm 0.3 \%$ in specific heat [8]. We used National Bureau of Standards (NBS) traceable standards for calibration of temperature, enthalpy, and specific heat throughout [9]. However, we have not yet quantified the precision of the measurements in this initial, exploratory task.

All samples were finely ground in air, carefully weighed, and sealed in aluminum containers supplied by Perkin-Elmer for the DSC instrument. Sealed sample containers were necessary because of the high vapor pressure of these compounds near and above their melting temperatures. Sample weights of a few milligrams $(\sim 20 \mu \mathrm{mol})$ provided the best sensitivity and are typical of the sample weights used with this kind of instrument.

Solid-solution mixtures were formed by grinding together several grams of the components and then using milligram portions for individual measuremenis. Reproducible behavior was normally obtained after the first temperature scan above the higher melting temperature of the two components.

Figure 2-1 shows a typical differential calorimetry scan of a solid solution ( 50 molar \% PG plus 50 molar \% NPG).* The temperature was increased at a rate of $20 \mathrm{k} / \mathrm{min}$ from room temperature to above the melting temperature. Results of the computer analysis of the two peaks were printed on the recording, which is reproduced in Figure 2-1. Notice that the enthalpy of transformation at $313 \mathrm{~K}$ is $87.4 \mathrm{~kJ} / \mathrm{kg}(20.9 \mathrm{cal} / \mathrm{g})$, several times larger than the latent heat of melting, $24.2 \mathrm{~kJ} / \mathrm{kg}(5.79 \mathrm{cal} / \mathrm{g})$. This is typical of these materials.

The inset in Figure 2-1 shows the arrangement of the sample container $S$ and the reference container $R$ in side-by-side but separately heated and controlled chambers. The platinum resistance thermometers provide the feedback signal that controls the independent heater circuits. As the support block for the two chambers is heated at a prescribed rate, vernier temperature control is maintained by the two individual chamber heaters. If the sample absorbs more energy than the reference, then more power is required in the sample chamber heater. The difference between the power requirements for these two chamber heaters provides the differential output signal.

In differential scanning calorimetry measurements of heats of transition and melting, no reference material is required, and an empty aluminum container is

*The three compounds used in the remainder of the report are as follows: $\mathrm{PE}=$ pentaerythritol, $\mathrm{PG}=$ pentaglycerine, and $\mathrm{NPG}=$ neopentyl-glycol. 


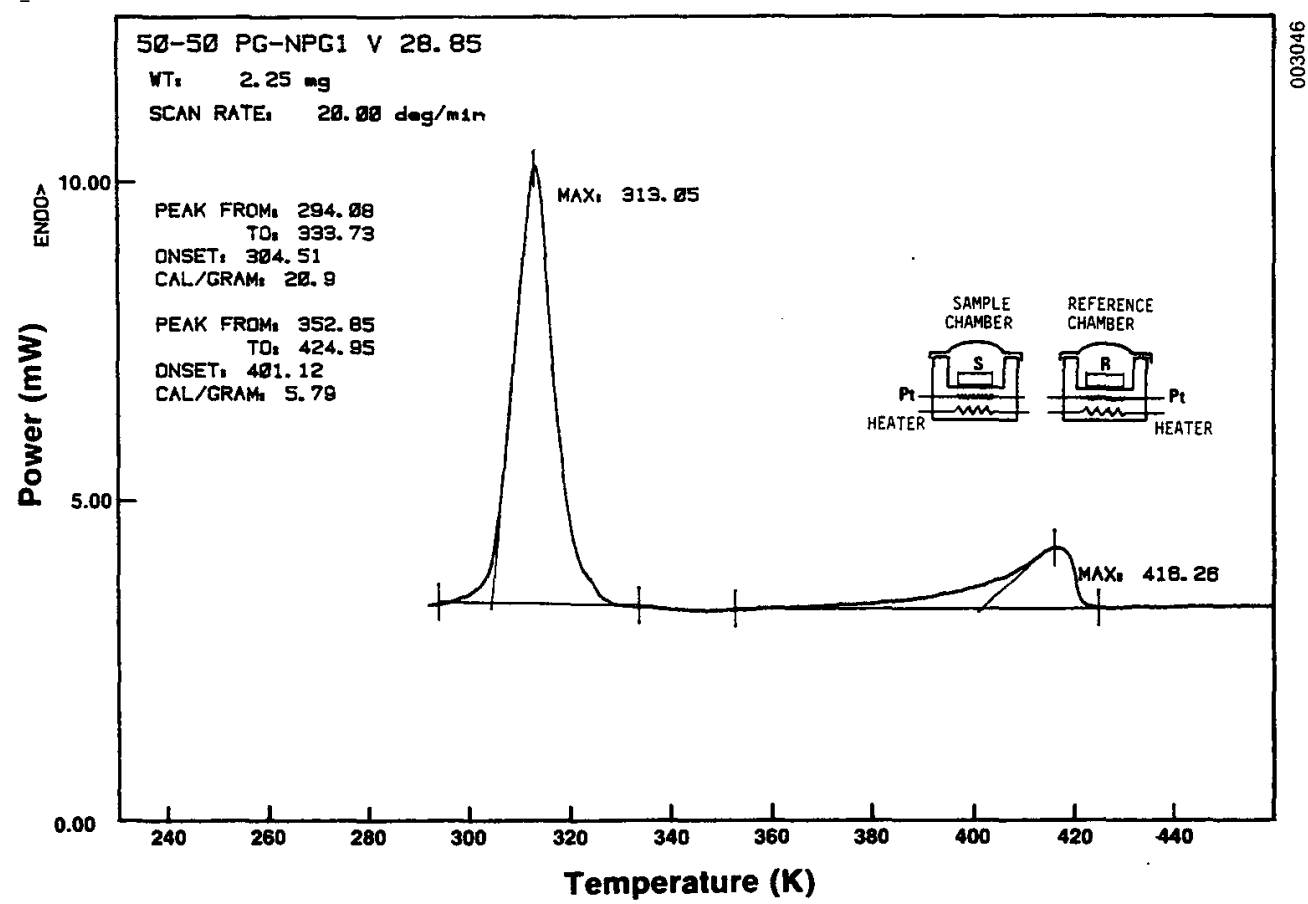

Figure 2-1. Typical Recording of Thermal Power Absorbed by a Solid-State Phase-Change Material as its Temperature Increases

used in the reference chamber. For specific heat measurements, a standard sapphire disk, sealed in an aluminum container, is used in the sample chamber during a separate differential scanning calorimetry scan. Sapphire is the preferred reference material because of the detailed specific heat data available for it from the National Bureau of Standards [10].

Figure 2-2 illustrates a typical set of three recordings required to measure the specific heat function of the solid solution (in this case 50 molar \% PE plus 50 molar \% PG). In this illustration, the temperature scale has been compressed and the relative separation of sample recording and sapphire reference standard recording has been exaggerated for clarity. First, the baseline recording is made with only empty aluminum containers in both chambers. This baseline recording indicates the inevitable nonlinearities in the temperature scan control and heat capacities of the instrument. The second recording with the standard sapphire reference sample in the sample chamber provides a signal above baseline that is just proportional to the specific heat of the standard. Finally, the third scan with the sample in the sample chamber provides a signal above baseline that is proportional to its specific heat (except in those regions where other processes such as solid-state transformations or melting are occurring). The ratio of the two signals (above baseline), corrected for the sample and standard weights, is the ratio of the specific heats. 


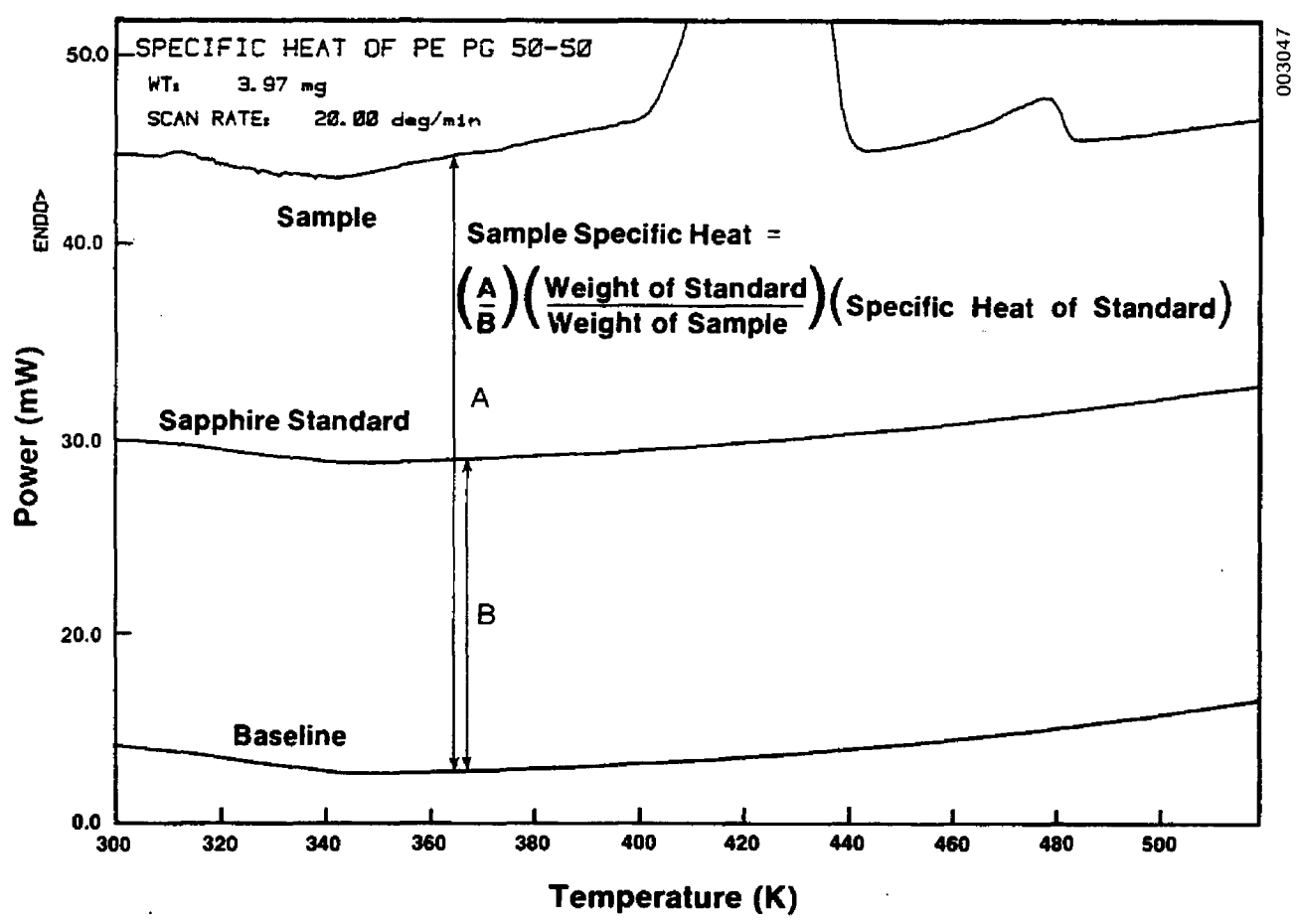

Figure 2-2. Typical Recordings for Heasuring the Specific Heat of a Solid-State Phase-Change Material by Differential Scanning Calorimetry

In these experiments, the measured specific heat is characteristic of the solid confined under its own saturated vapor pressure:

$$
c_{s}=c_{p}-T\left(\frac{\partial P}{\partial T}\right)_{s}\left(\frac{\partial V}{\partial T}\right)_{p},
$$
where $(\partial P / \partial T)_{s}$ is the slope of the vapor pressure curve and $(\partial V / \partial T)_{P}$ is the
coefficient of volumetric thermal expansion.

Commercially available chemicals were used in all of the experiments reported, but similar results were obtained with recrystallized compounds and with technical grade materials. Neopentyl-glycol (practical grade) and pentaerythrito 1 (ungraded) come from Eastman Kodak Co., Rochester, N.Y.; pentaglycerine (ungraded) comes from Aldrich Chemical Co., Milwaukee, Wis. 


\title{
SECTION 3.0
}

\author{
RESULTS
}

\subsection{THERMOPHYSICAL PROPERTIES}

The results of measurements on binary solid solutions of pentaerythritol (PE), pentaglycerine (PG), and neopentyl-glycol (NPG) are summarized in Table 3-1. In general, it appears that these three homologs form solid solutions in all proportions; however, the possible existence of second phases of different crystal structure has not been ruled out.

Figure 3-1 shows a series of differential scanning calorimetry recordings for different compositions of the solid solution $P G_{x} N P G_{1-x}$ ranging from pure $P G$ $(\mathrm{x}=1)$ to pure NPG. Notice that some of the solid-solid phase transformation peaks show some evidence of structure, particularly for compositions near $x=0$. Similarly, structure is evident in transition peaks for the mixtures of PE + NPG and PE + PG (see Figure 3-2). This structure may be evidence of separate (crystal) phases or of local short-range ordering of molecules into clusters.

Figure 3-3 graphically summarizes the measurements of enthalpies of transformation for the $P G_{X} N^{N G} G_{1-x}$ solid solutions. Notice that the transition temperatures and enthalpies follow the same trend. The entropies of transformation and of melting are shown in Figure 3-4 for these same materials. Figure 3-5 summarizes results for all three binary solid solutions.

We measured specific heat for all our solid solutions at temperatures ranging from near room temperature to above the melting temperature. Figure 3-6 shows typical results for the mixture $50 \% \mathrm{PE}+50 \% \mathrm{PG}$ in comparison with the specific heats of the pure components. Some of the curvature in the specific heat curves occurs because the phase transformation (solid-state and melting) peaks have not been subtracted. Figure 3-7 shows the trends in specific heats as a function of solid-solution composition for the PG-NPG mixtures.

When these mixtures are cycled repeatedly through the solid-state transition, the phase change appears to be fully reversible. A single composition was tested by repeatedly cycling 732 times. Although there was some variation in the shape of the differential scanning calorimetry peaks, the measured enthalpies of transformation changed by no more than about $3 \%$, within the uncertainty of the measurements (see Figure 3-8).

\subsection{UNDERCOOLING OF THE SOLID-STATE TRANSFORMATION}

All of the solid-state phase-change materials tested have exhibited large amounts of undercooling. Figure 3-9 illustrates the undercooling phenomenon shown by differential scanning calorimetry. During heating (right portion of Figure 3-9), the thermal power is absorbed over a range of temperatures dependent upon the heating rate. Upon cooling (left portion of Figure 3-9), the reverse transformation liberates the stored thermal energy at much lower temperatures, which are again dependent on the cooling rate. At very high 
Table 3-1. Summary of Thernal Properties of Polyol Solid Solutions

\begin{tabular}{cccc}
\hline $\begin{array}{c}\text { Molar Percent } \\
\text { Pentaerythritol }\end{array}$ & $\begin{array}{c}\text { Phase-Change } \\
\text { Temperature } \\
(\mathrm{K})\end{array}$ & $\begin{array}{c}\text { Enthalpy of } \\
\text { Transformation } \\
(\mathrm{kJ} / \mathrm{mol})\end{array}$ & $\begin{array}{c}\text { Specific } \\
\text { Heat }^{\mathrm{a}} \\
(\mathrm{kJ} / \mathrm{mol} \mathrm{K})\end{array}$ \\
\hline \multicolumn{2}{r|}{ Pentaerythritol/Pentaglycerine } & & \\
\hline 100.0 & 460 & 36.8 & 0.387 \\
86.1 & 442 & 31.8 & 0.387 \\
72.6 & 422 & 28.8 & 0.394 \\
57.0 & 401 & 21.3 & 0.393 \\
50.0 & 397 & 22.3 & 0.417 \\
37.0 & 381 & 21.6 & 0.411 \\
22.7 & 373 & 18.6 & 0.381 \\
11.2 & 361 & 17.4 & 0.321 \\
0.0 & 355 & 16.7 & 0.337 \\
\hline
\end{tabular}

\begin{tabular}{cccc}
\hline $\begin{array}{c}\text { Molar Percent } \\
\text { Pentaglycerine }\end{array}$ & $\begin{array}{c}\text { Phase-Change } \\
\text { Temperature } \\
(\mathrm{K})\end{array}$ & $\begin{array}{c}\text { Enthalpy of } \\
\text { Transformation } \\
(\mathrm{kJ} / \mathrm{mol})\end{array}$ & $\begin{array}{c}\text { Specific } \\
\text { Heat } \\
\text { (kJ/mol K) }\end{array}$ \\
\hline Pentaglycerine/Neopentyl-Glycol & & \\
\hline 100.0 & 362 & 16.7 & 0.330 \\
87.5 & 350 & 15.7 & 0.349 \\
75.0 & 335 & 12.2 & 0.343 \\
60.0 & 320 & 11.7 & 0.290 \\
50.0 & 313 & 9.95 & 0.268 \\
40.0 & 299 & 8.41 & 0.292 \\
25.0 & 297 & 8.16 & 0.265 \\
12.5 & 300 & 7.03 & 0.296 \\
0.0 & 321 & 12.6 & 0.287 \\
\hline
\end{tabular}

\begin{tabular}{cccc}
\hline $\begin{array}{c}\text { Molar Percent } \\
\text { Pentaerythritol }\end{array}$ & $\begin{array}{c}\text { Phase-Change } \\
\text { Temperature } \\
(\mathrm{K})\end{array}$ & $\begin{array}{c}\text { Enthalpy of } \\
\text { Transformation } \\
(\mathrm{kJ} / \mathrm{mol})\end{array}$ & $\begin{array}{c}\text { Specific } \\
\text { Heat }^{\mathrm{a}} \\
(\mathrm{kJ} / \mathrm{mol} \mathrm{K})\end{array}$ \\
\hline Pentaerythritol/Neopentyl-Glycol & & \\
\hline 100.0 & 460 & 36.8 & 0.387 \\
87.5 & 453 & 28.1 & 0.376 \\
75.0 & 448 & 24.7 & 0.418 \\
50.0 & 442 & 10.8 & $\mathrm{~b}$ \\
25.0 & 392 & 5.60 & 0.361 \\
12.5 & 312 & 8.79 & 0.344 \\
0.0 & 326 & 12.6 & 0.287 \\
\hline
\end{tabular}

${ }^{a}$ Specific heat values are for Phase II of the material, between the phase-change temperature and the melting temperature.

$b_{\text {Not }}$ well defined because of proximity of phase-change and melting temperatures. 


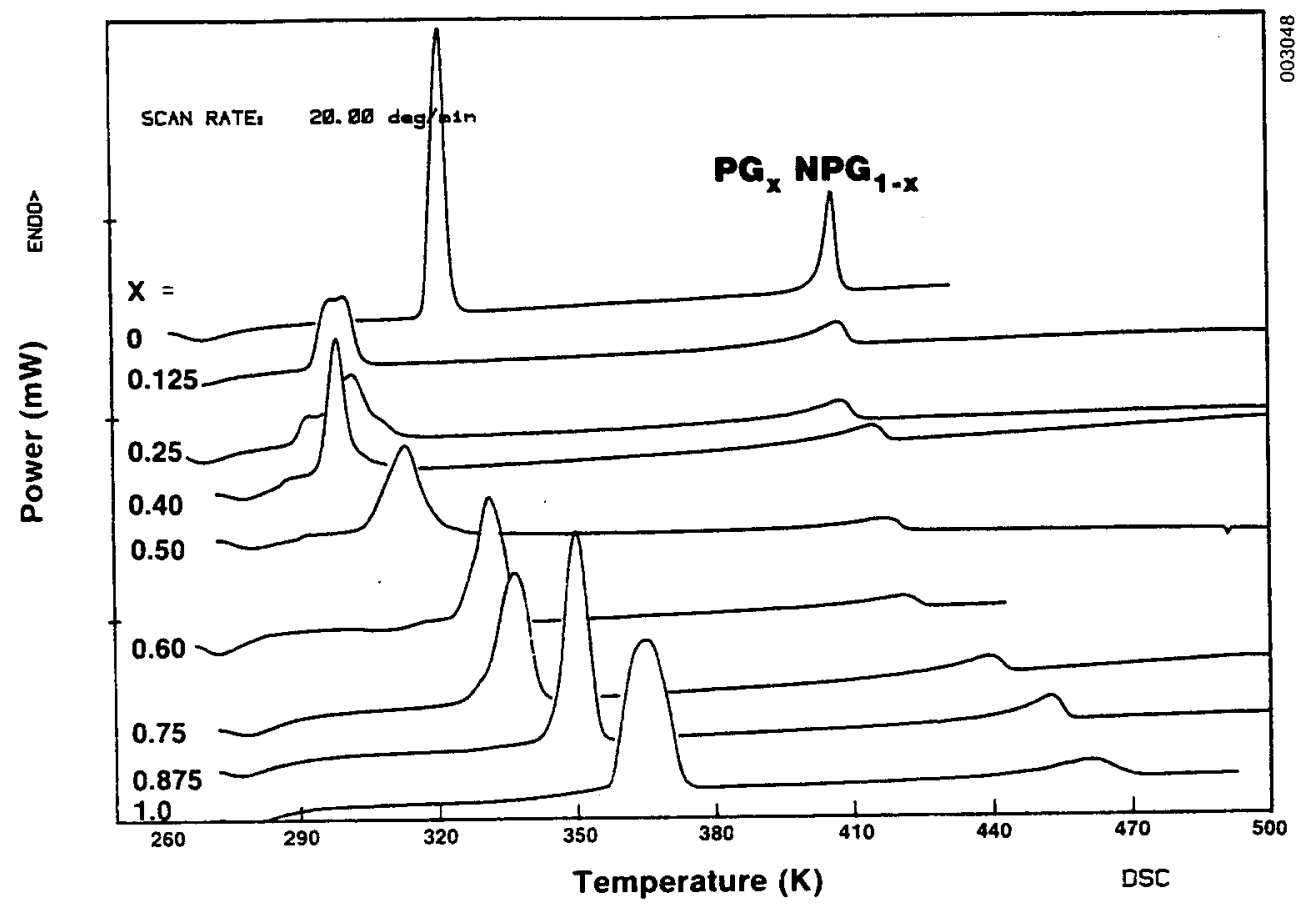

Pigure 3-1. Differential Scanning Calorimetry Recordings of Solid Solution Mixtures of PG and NPG $(x=$ molar fraction of $P G$ in the mixture)

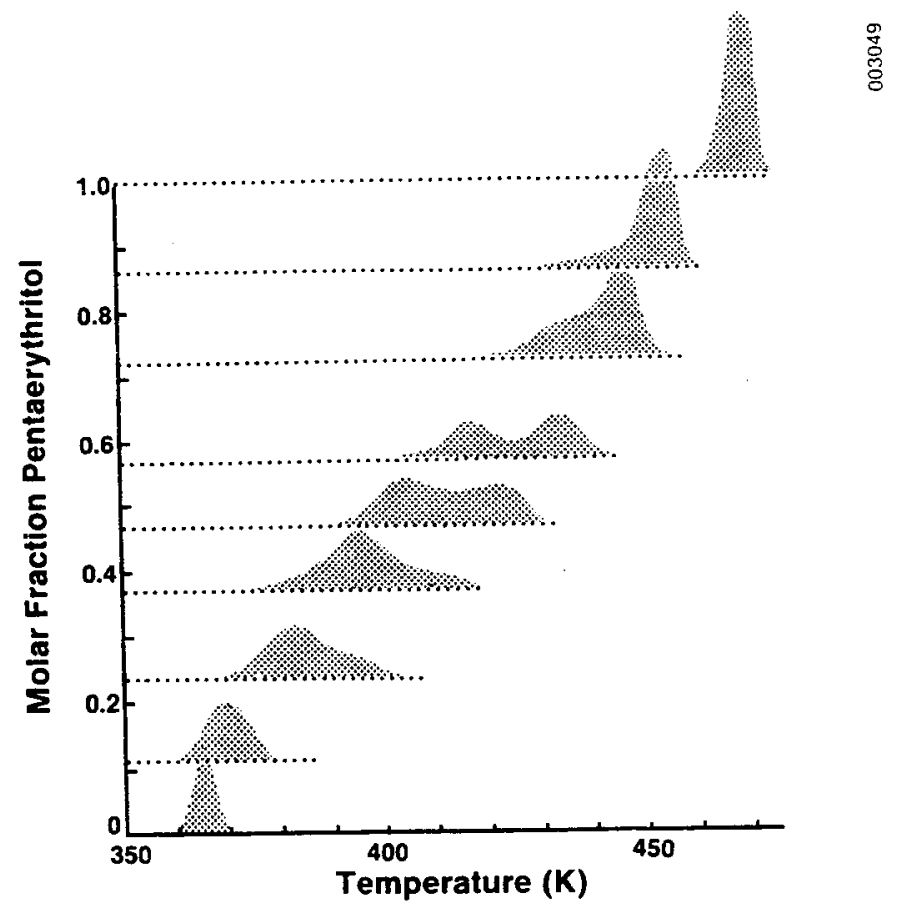

Figure 3-2. Differential Scanning Calorimetry of Solid Solutions of PE in PG 


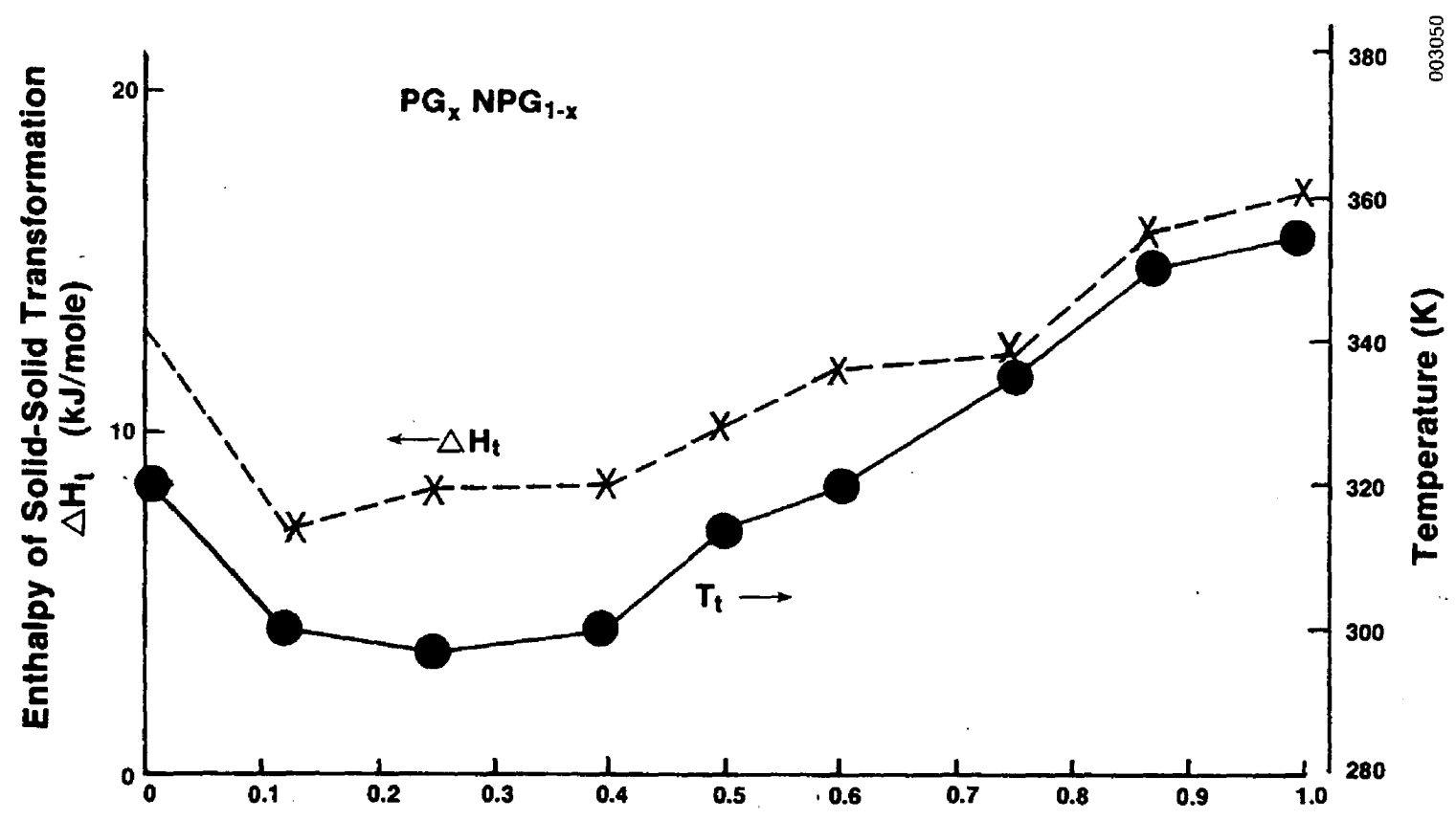

$X$, Molar Fraction Pentglycerine

Figure 3-3. Measured Enthalpies and Temperatures of Solid-State Transformation for Mixtures of PG in NPG (Heating rate of $20 \mathrm{~K} / \mathrm{min}$ )

heating and cooling rates, the difference between the peak transformation temperatures during heating and cooling is as large as $43^{\circ} \mathrm{C}$. However, at more realistic heating and cooling rates for passive solar applications, the temperature difference between heating and cooling peaks is reduced to about $16^{\circ} \mathrm{C}$. Even this difference is large compared to the expected temperature swing in thermal energy storage systems for passive solar applications.

Shifts in peak temperature and undercooling can be understood in terms of the transformation kinetics. If the transformation is a first-order reaction, then the rate at which the concentration $C_{I}$ of transformed material increases can be expressed in terms of a reaction rate constant $K$ as

$$
\frac{\mathrm{dC}_{\mathrm{I}}}{\mathrm{dt}}=\mathrm{kC} \mathrm{C}_{\mathrm{I}}
$$

At any time during the transformation, the fraction of the mass already transformed is given by:

$$
\ln c_{I}=\ln C_{I}(0)+\int_{t_{0}}^{t} K d t=\int_{t_{0}}^{t} K d t \text {, }
$$




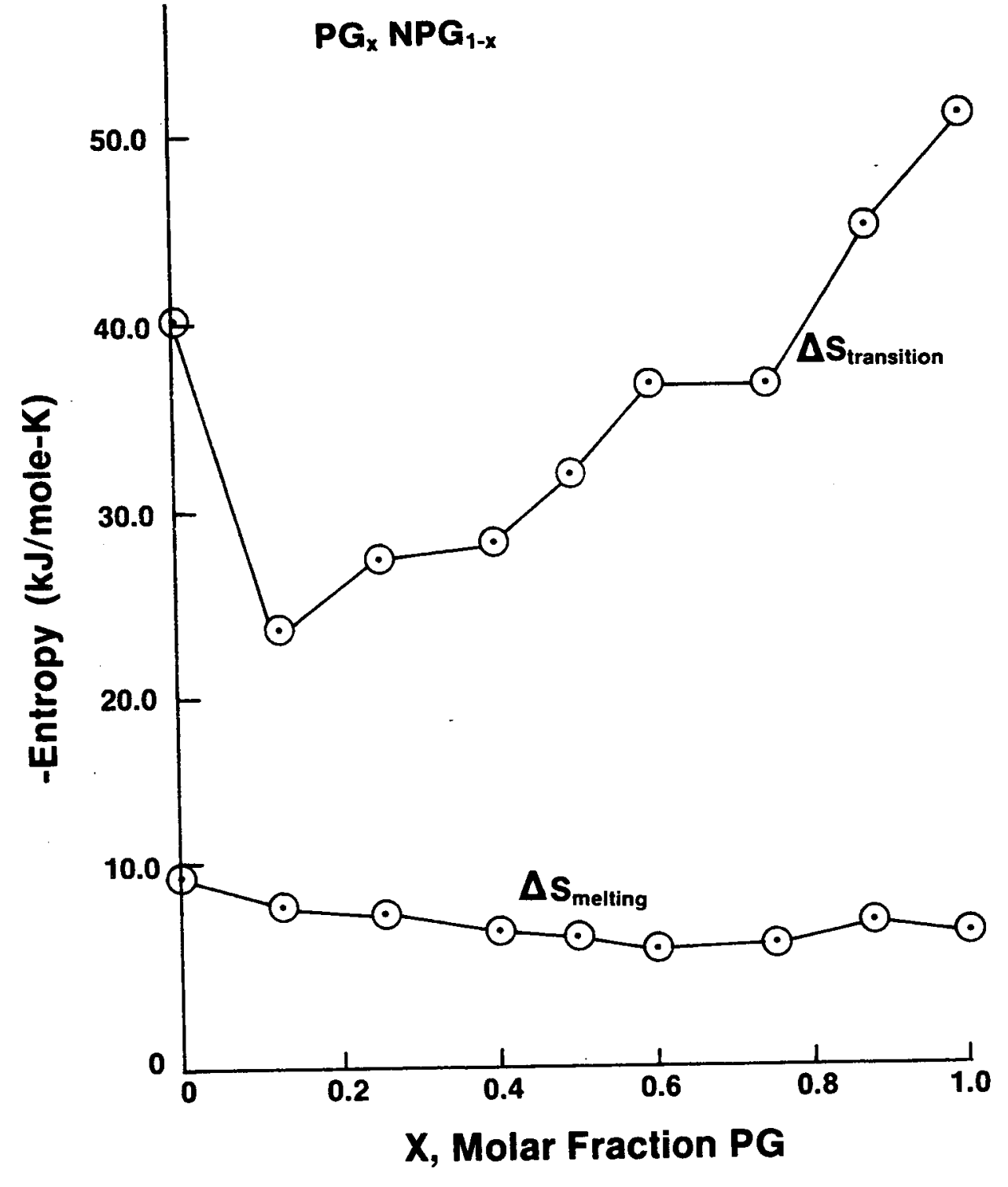

Figure 3-4. Entropies of Transformation for Solid-Solution Mixtures of $P G$ in NPG 


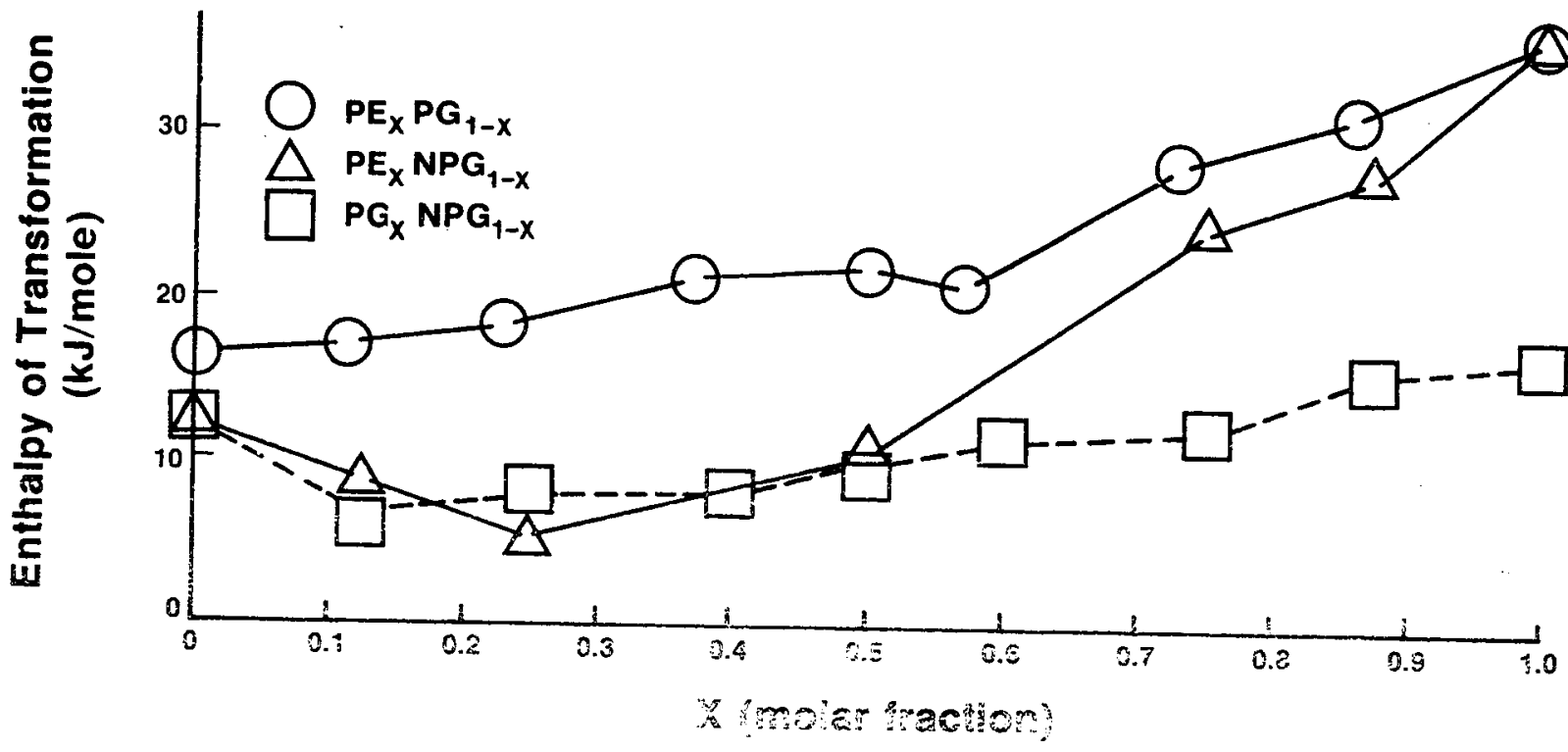

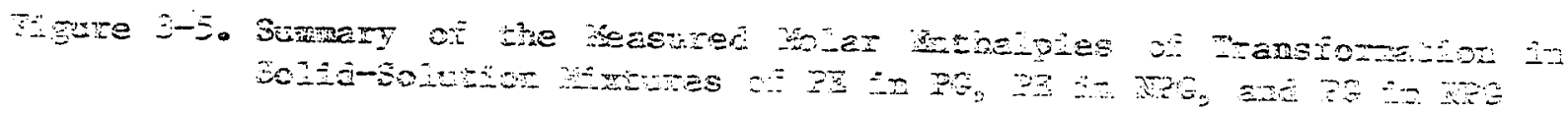

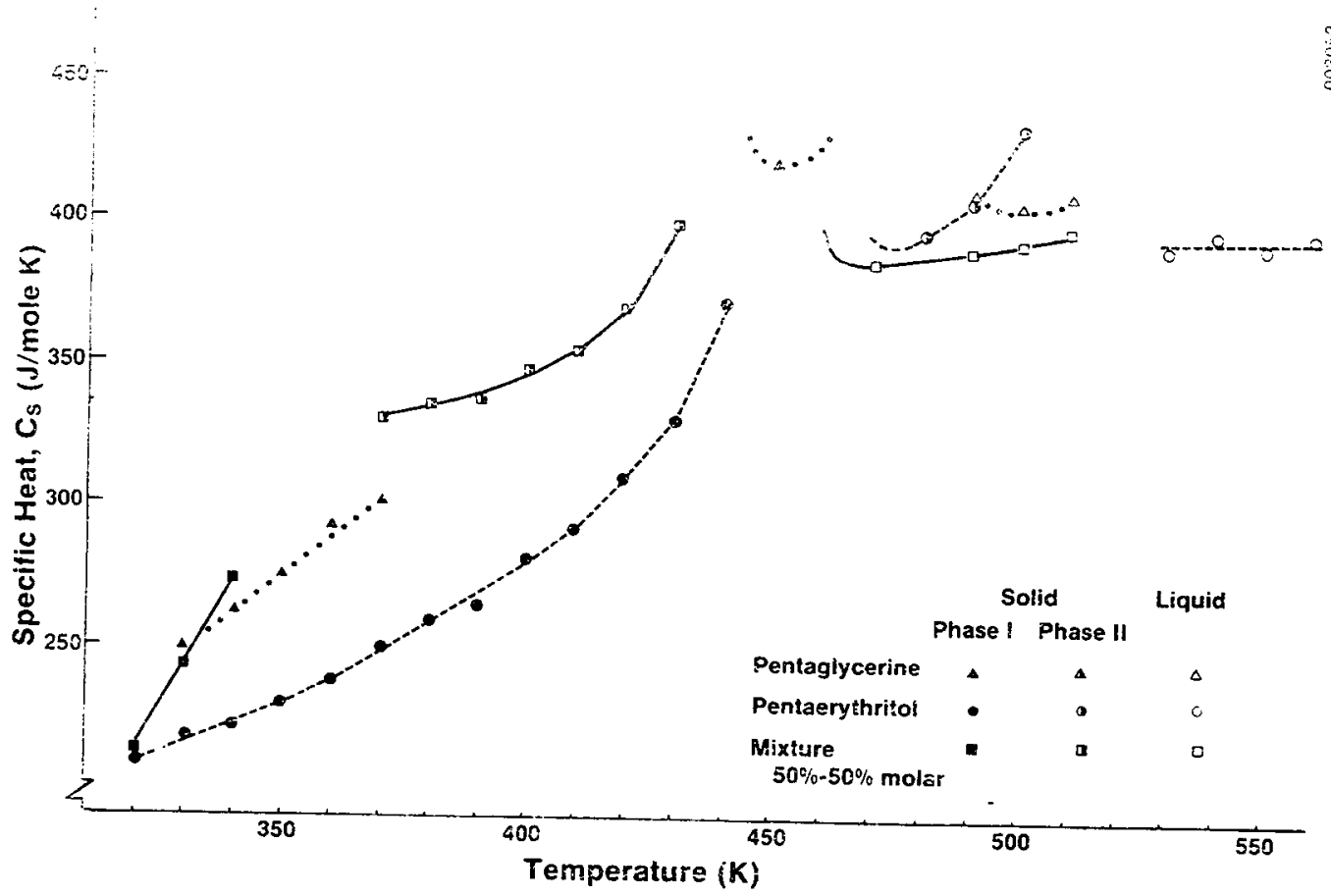
Figure 3-6. Measured Specific Heats of PG, PE, and a 50\%-50\% Wolar Solid
Solution 


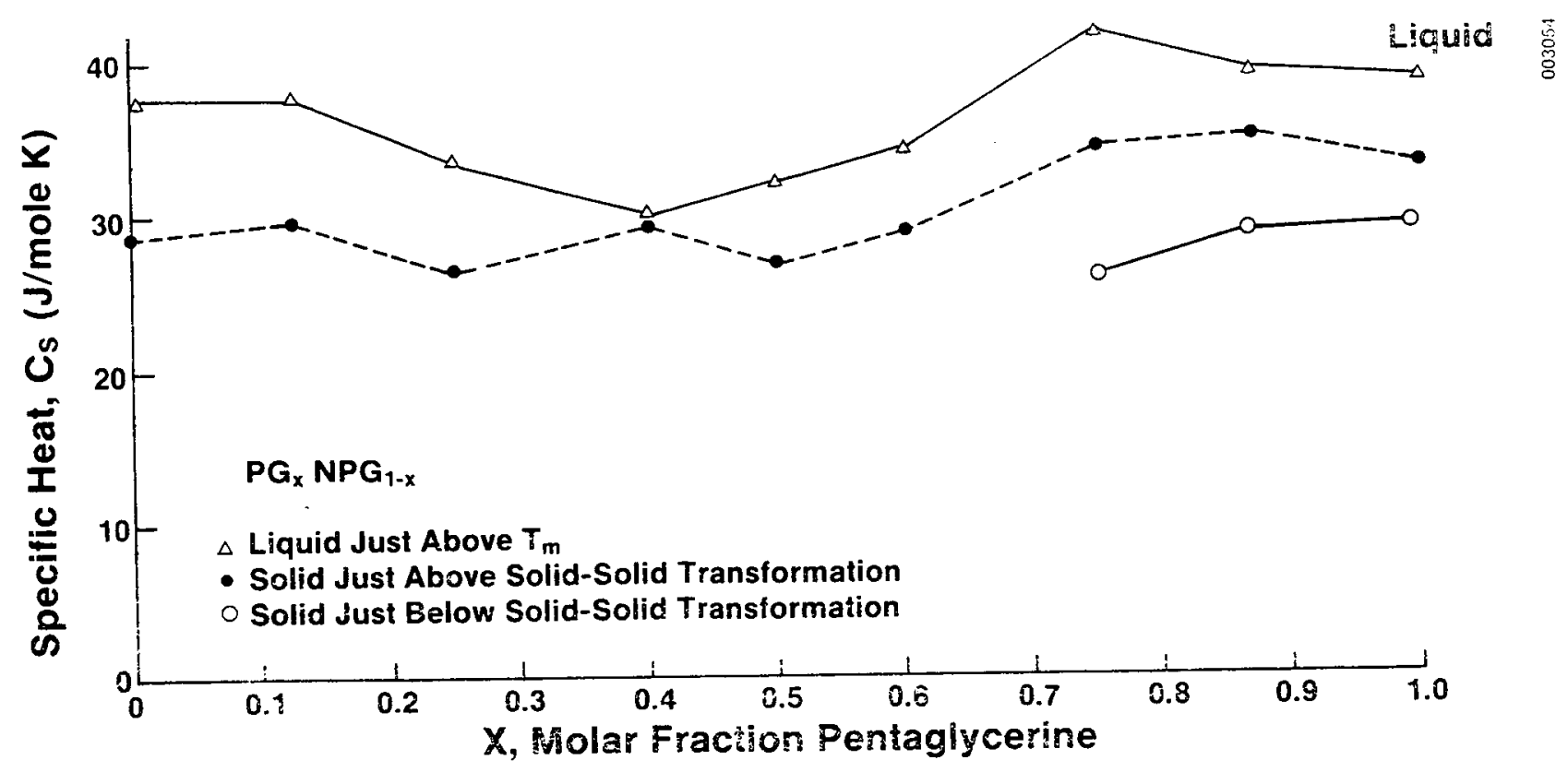

Figure 3-7. Measured Specific Heats of Mixtures of PG and NPG

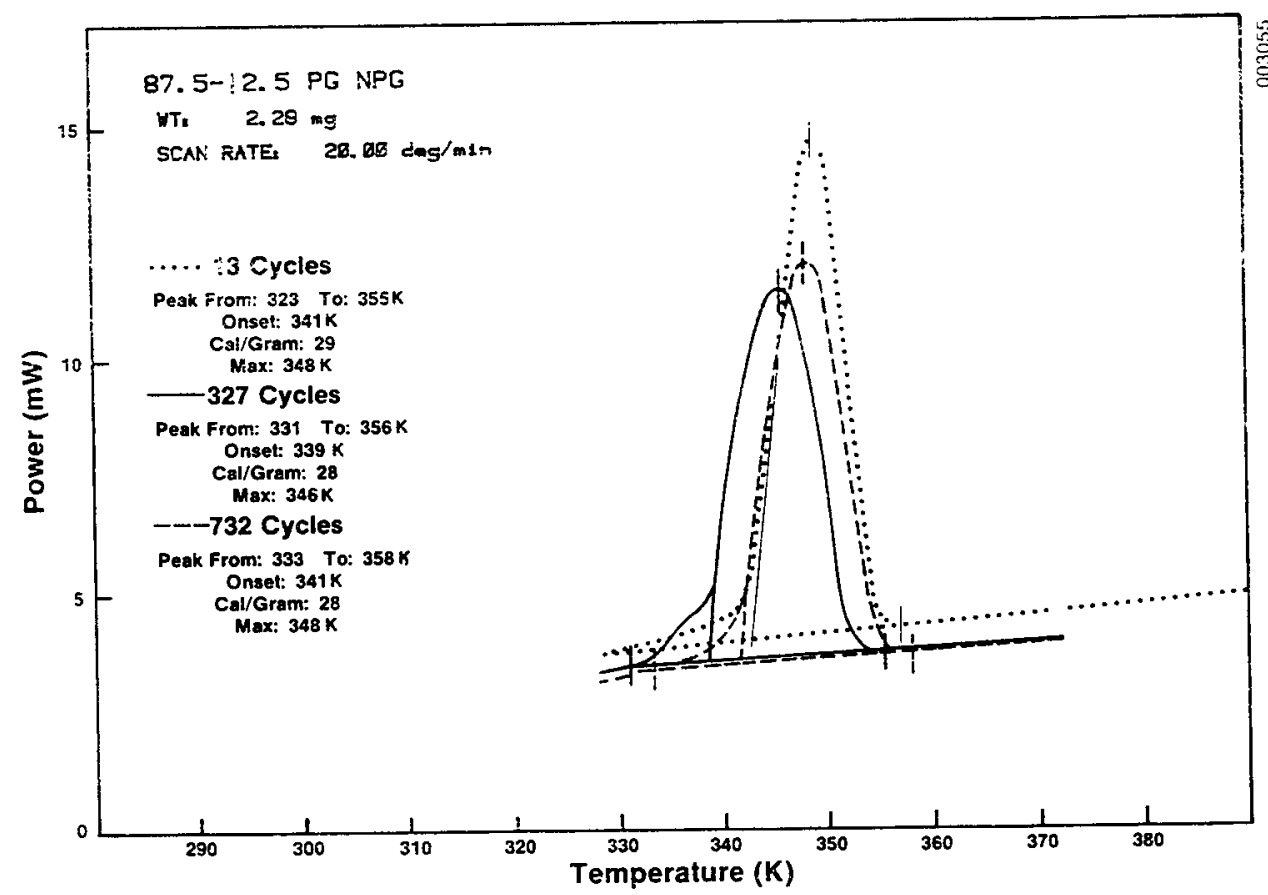

Figure 3-8. Differential Scanning Calorimetry Recordings of the Thermal Absorption Peak in an $87.5 \mathrm{~mol} \%$ Solution of Fô in NPG 


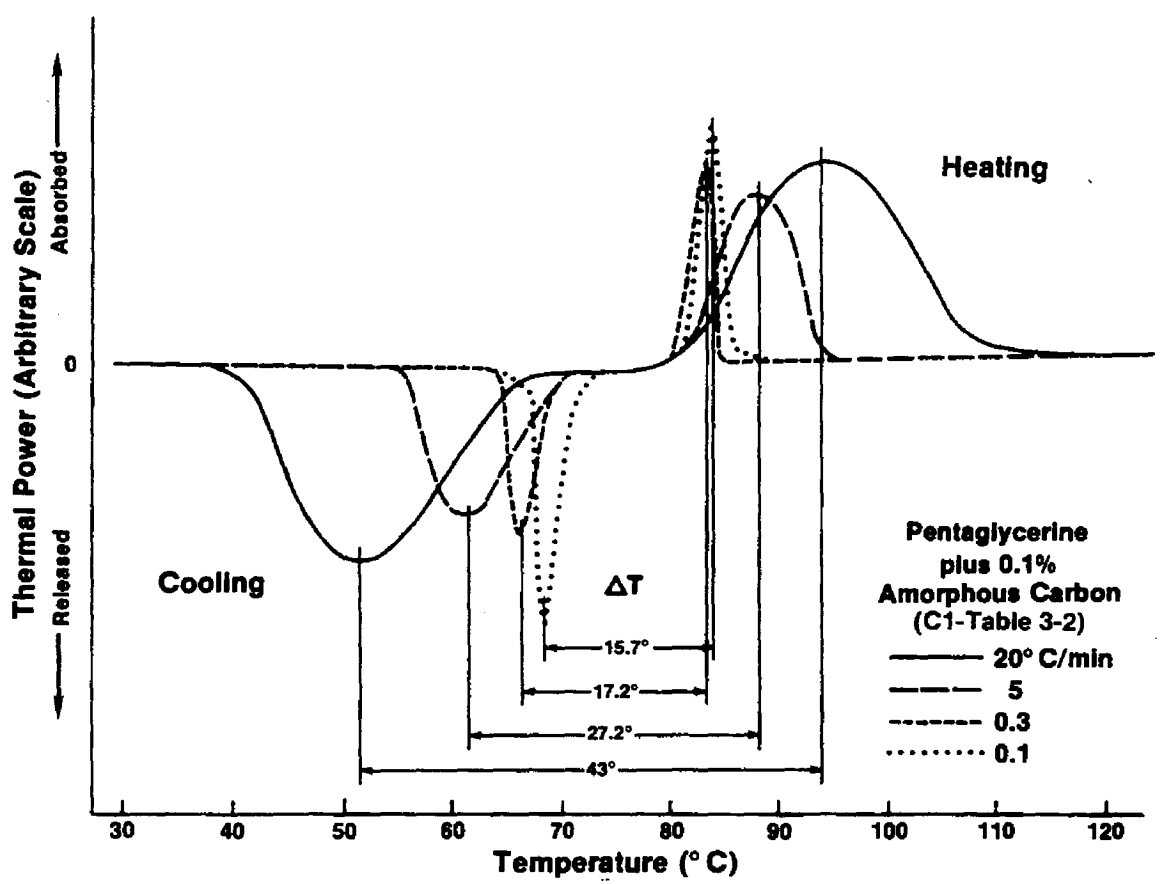

Figure 3-9. Differential Scanning Calorimetry Recordings of the Thermal Absorption and Thermal Energy Release from PG at Different Heating and cooling Rates. (The temperature difference $\Delta T$ between the solid-state transition during heating and the reverse transition during cooling is an undercooling effect attributable to the kinetics of transformation.)

and if the heating (or cooling) rate is a constant $\mathrm{H}$ (or $\mathrm{C}$ ), then

$$
T=T_{0}+H\left(t-t_{0}\right) \text { or } T=T_{0}-C\left(t-t_{0}\right),
$$

and

$$
\mathrm{dT}=\mathrm{Hdt} \text { or } \mathrm{dT}=-\mathrm{Cdt} \text {. }
$$

Then Eq. 3-2 can be expressed as

$$
\ln C_{\mathrm{I}}=\frac{1}{\mathrm{H}} \int_{\mathrm{T}_{\mathrm{O}}}^{\mathrm{T}_{\mathrm{O}}+\mathrm{H}\left(\mathrm{t}-\mathrm{t}_{\mathrm{o}}\right)} \mathrm{KdT} \text {. }
$$

At any given concentration of transformed material (e.g., 50\%, corresponding approximately to the peak of the differential scanning calorimetry recording),

$$
\ln C_{I}=\text { constant }=\frac{1}{H} \int_{T_{0}}^{T_{0}+\Delta T} K d T \text {, }
$$

and

$$
\int_{\mathrm{T}_{0}}^{\mathrm{T}_{\mathrm{O}}+\Delta \mathrm{T}} \mathrm{KdT} \propto \mathrm{H} .
$$


Over the narrow range of temperatures around the peak transformation temperature $T_{p}$, the reaction rate may be approximated by the first few terms in a Taylor expansion:

$$
K(T)=K\left(T_{p}\right)+T \frac{d K\left(T_{p}\right)}{d T}+\frac{T^{2}}{2} \frac{d^{2} K\left(T_{p}\right)}{d T^{2}}+\cdots \cdot
$$

If the first term alone is used, Eq. 3-7 yields the simple linear relation:

$$
\Delta \mathrm{T} \propto \frac{\mathrm{H}}{\mathrm{K}\left(\mathrm{T}_{\mathrm{p}}\right)}+\ldots .
$$

suggesting that $\Delta \mathrm{T}$, the width of the transition peak, increases monotonically with the heating and cooling rate; hence the temperature difference between heating and cooling peaks should increase with the heating and cooling rate.* Although the data points are widely scattered, the trend is clearly shown in Figures 3-9 and 3-10.

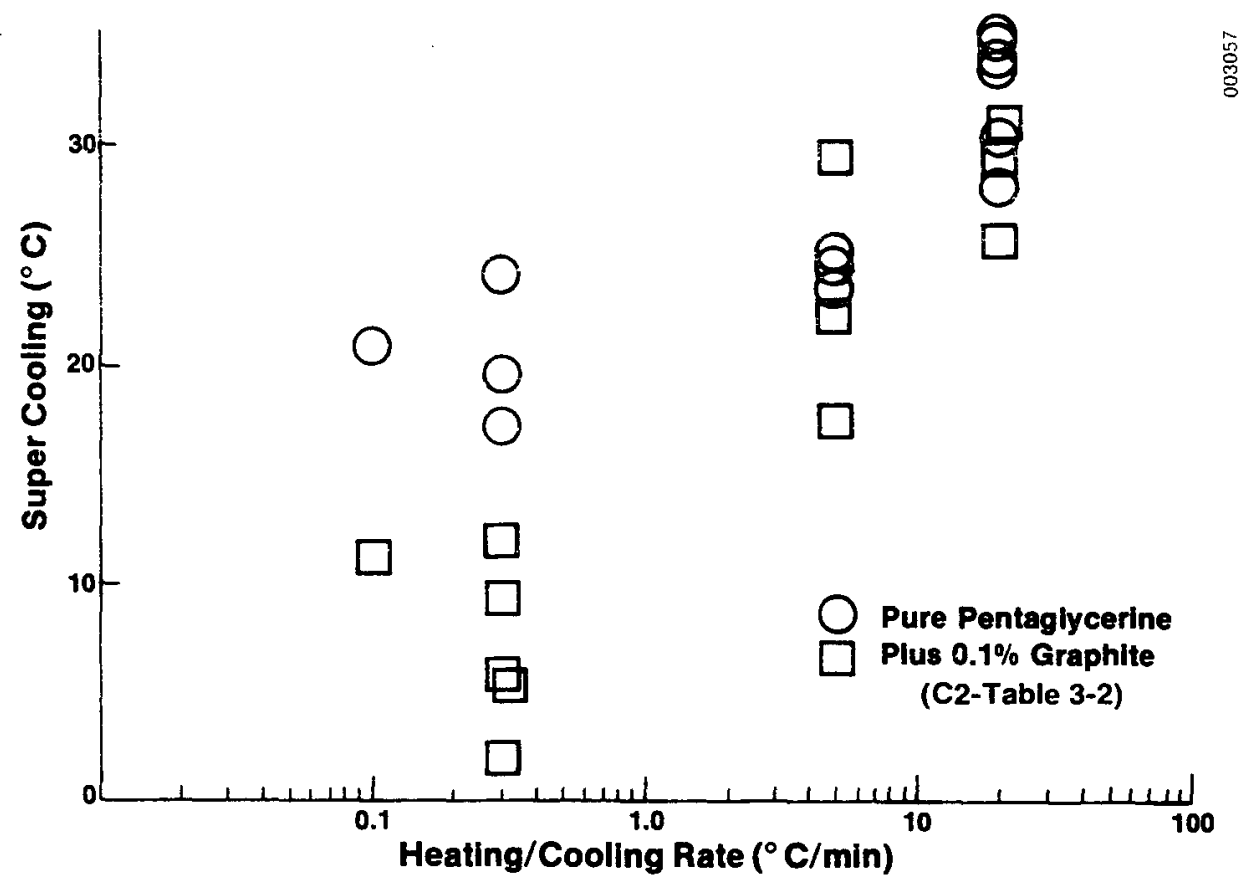

Figure 3-10. Effect of 0.1 wt $\%$ Addition of Powdered Graphite on the Under-
cooling of PG

*Including additional terms in the approximation for $\mathrm{K}(\mathrm{T})$ would not change the conclusion that the undercooling is expected to increase with heating and cooling rate, but would make the dependence nonlinear. 
The solid-state transformation proceeds by a thermally activated process characterized by an activation energy (which is unrelated to the transformation enthalpy). The reaction rate constant is expressed in terms of this activation energy $\Delta E^{\prime}$ and temperature as:

$$
\mathrm{K}=\mathrm{A} \exp -\frac{\Delta \mathrm{E}^{\prime}}{\mathrm{kT}},
$$

where $k$ is Boltzmann's constant and $A$, the preexponential factor, includes the statistical partition functions of molecules before and after transformation and is weakly dependent on temperature. Normally the temperature dependence of $\mathrm{A}$ is negligible compared to the exponential factor, and $\mathrm{A}$ is considered a constant.

Thomas and Clarke [11] have shown that the rate constant for a first order reaction can be easily determined as a function of temperature from a differential scanning calorimetry recording. At any temperature within the peak, the instantaneous value of $\mathrm{K}(\mathrm{T})$ is equal to the ratio of the thermal power being absorbed (or released) to the amount of the total energy not yet absorbed (or released).

$$
\mathrm{K}(\mathrm{T})=\frac{\mathrm{dH} / \mathrm{dt}}{\text { area remaining under curve }} \text {. }
$$

Figure 3-1i shows several logarithmic plots of $K$ versus reciprocal temperature (Arrhenius plot).

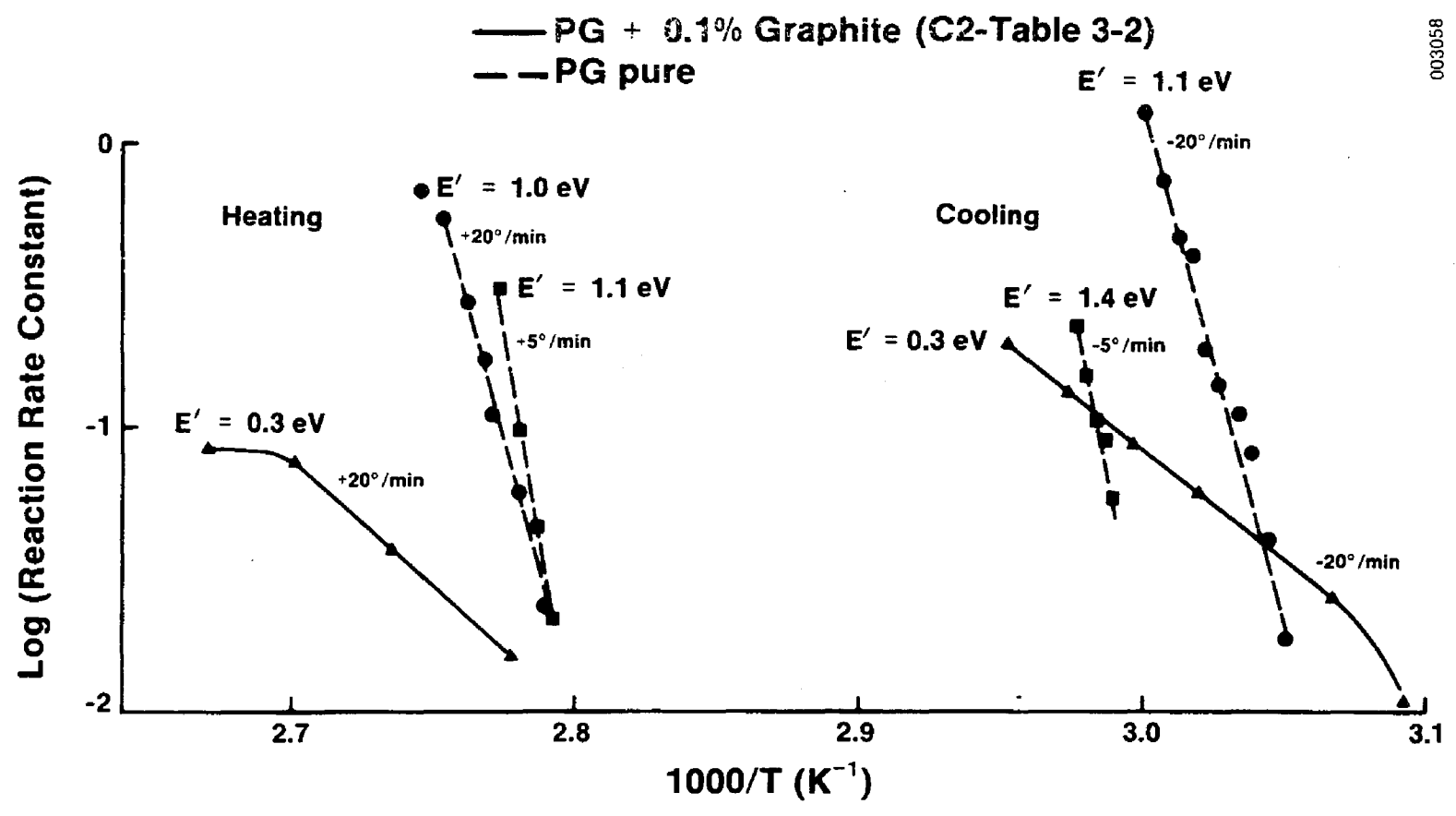

Figure 3-11. Arrhenius Plots of the Reaction Rate Constants for Solid-State Transformations in PG 
From Eq. 3-10 activation energy is computed as

$$
\Delta \mathrm{E}^{\prime}=-\mathrm{k} \frac{\mathrm{d} \ln \mathrm{k}}{\mathrm{d}(\mathrm{l} / \mathrm{T})}=-\mathrm{k}(\text { slope })
$$

Similarly, the preexponential factor can be determined from

$$
\ln A=\lim _{(1 / T) \rightarrow 0} \ln K=\ln A-\frac{\Delta E^{\prime}}{k T}
$$

\subsection{NUCLEATION OF THE SOLID-STATE TRANSFORMATION}

The solid-state transformation in a pure compound may be homogeneously nucleated but typically is heterogeneously nucleated by crystal imperfections such as dislocations or stacking faults. The activation energy that characterizes the rate-limiting step in this nucleation process is the activation energy discussed in the preceding section. In principal, one can always reduce the activation barrier to nucleation by introducing a nucleating agent--in effect, a catalyst on which the nucleation reaction occurs heterogeneously.

Reducing the activation energy would correspondingly increase the transition rate and decrease the degree of undercooling. This dependence can be seen in the linear approximation of Eq. 3-9, which can be rewritten:

$$
\Delta \mathrm{T} \propto \frac{\mathrm{H}}{\mathrm{A}} \exp \frac{\Delta \mathrm{E}^{\prime}}{\mathrm{kT}_{\mathrm{p}}}
$$

The width of the peak and the temperature differences between heating and cooling transition peaks increase with increasing $\Delta \mathrm{E}^{\prime}$.

An experimental search for suitable nucleating agents was successful. Table 3-2 lists the agents tested. The addition of a very small quantity of "amorphous graphite" $(0.1$ wt \%) was sufficient to reduce the nucleation activation energy from 1.4 to $0.35 \mathrm{eV}$ (134 to $33 \mathrm{~kJ} / \mathrm{mole}$ ) and decrease the undercooling at any heating or cooling rate.

Figure 3-10 shows the effect of the nucleating agent on the undercooling of pentaglycerine. At heating and cooling rates typical of passive solar applications $\left(\sim 0.1^{\circ} \mathrm{C} / \mathrm{min}\right)$, the undercooling is reduced by a factor of two or more. More measurements are required to determine precise undercooling at these very low heating and cooling rates.

\subsection{INFRARED SPECTROSCOPY}

Fourier transform infrared (FTIR) spectroscopy was used to monitor the molecular spectra over a range of temperatures including the solid-state transformation temperature. Changes in these spectra may indicate the nature of the changes in molecular coordination responsible for the solid-state transformation. 
Tabie 3-2. Materials Tested for Hucleation of Soidd-State Phase-Change Bacerial Transformation

Material Supplier Description $\begin{gathered}\text { Nucleation } \\ \text { Effective }\end{gathered}$

\section{Carbons}

\section{$\mathrm{Cl}$ "Amorphous graphite" Dixon Crucible Co. 167 Wayne St.} Jersey City, NJ 07303

C2 "Microfine graphite" Dixon

C3 Decoloring carbon (Darco brand, GGO)

C4 Animal charcoaI " bone Siack," "bone char")

\section{Silicas}

Sl "Microsil No. 2"

S2 Amorphous silica i MS IL-A-108H
Illinois Mineral Co. 2035 Washington ive. Cairo, IL 62914

Ilinois Mineral Co. 2035 Washington Ave. Cairo, IL 62914

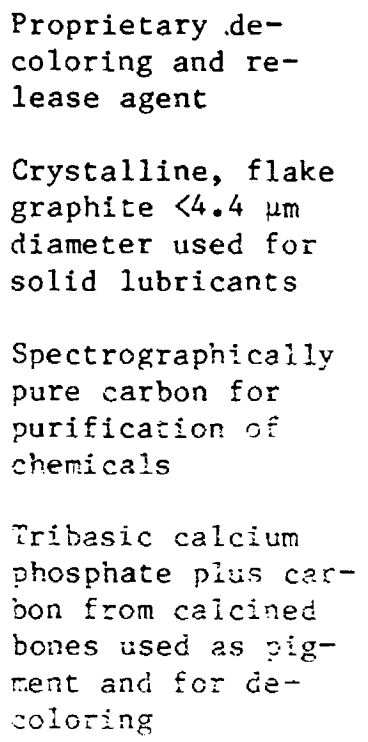

No

No

Ingredient in pot-

No

$$
77 \text { Lipan St. }
$$$$
\text { Denver, CO }
$$

ters' clays and separators

Ash Grove Cement Co. 1000 Ten Main Center Kansas City, MO 64110

Mallinkrodt Chemical Co. 675-7 Brown Road

Reagent grade chemNo St. Louis, MO 63134

No

Yes

o

Miscellaneous
CS Calcium sulfate $\left(\mathrm{CaSO}_{4} \cdot 2 \mathrm{H}_{2} \mathrm{O}\right)$ 
For this set of experiments, a temperature-controlled sample holder with a vacuum-insulated jacket was used in the Nicolet Mode1 7199 FTIR spectrometer [12]. Figure 3-12 shows a schematic diagram of the sample holder. Samples were prepared as solid powder dispersions in pressed pellets of potassium bromide.

Spectra were obtained at regular intervals of steady-state temperature. The average heating and cooling rates were kept very 1 ow $\left(\sim 0.3^{\circ} \mathrm{C} / \mathrm{min}\right)$ and excess temperature was held to $\left\langle 2^{\circ} \mathrm{C}\right.$ by the proportional temperature controller.

At each temperature, an infrared spectrum was recorded and stored digitally. Figure 3-13 shows a set of such spectra for PG heated in steps from 59 to $120^{\circ} \mathrm{C}$. Notice the shift in the hydroxyl bond absorption peak between $79^{\circ}$ and $89^{\circ} \mathrm{C}$. This shift is reversible and appears to correspond with the solid-state transformation at $82^{\circ} \mathrm{C}$.

Figure 3-14 shows a set of infrared spectre for PE heated and then coojed in

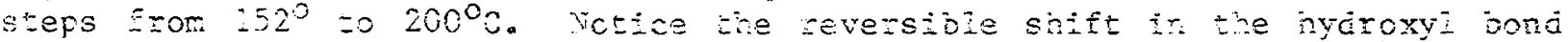

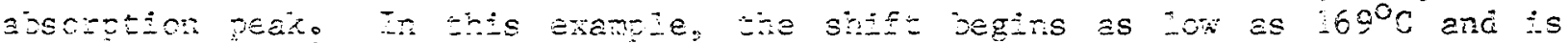

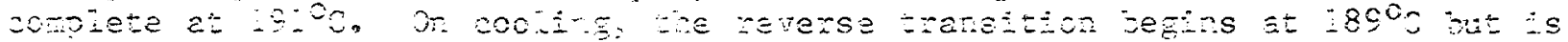

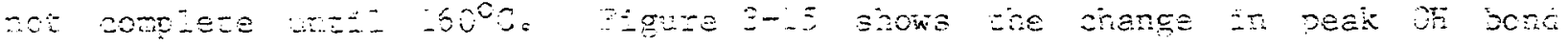
bsorpticr Inequen -

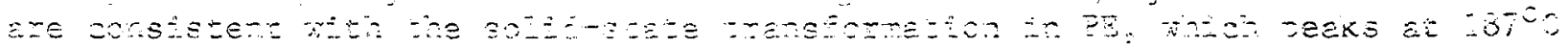

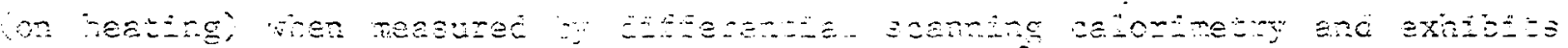

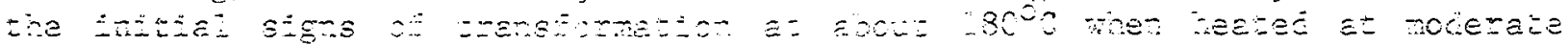
ratas.

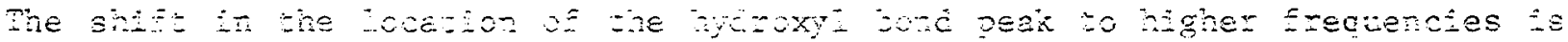

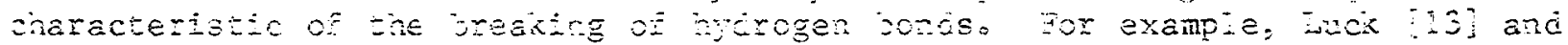
others have shwr ches yyrogen jonds are stmed when aicohol mojecuies associate to form dimers and pojyers in soiutions mis hyrogen bori Eormation causes shifts in the $\mathrm{OH}$ bonds as summarized in Table 3-3. The magrizude of the $\mathrm{OH}$ peak shitt when an aicohol aimer is formed is approximateiy -140 cn comparable to the +60 to $+30 \mathrm{~cm}^{-1}$ peaik shift seen during cooling of NPG, PG, and $\mathrm{PE}$.

At the solid-state transformation temperature $T_{t}$, the Gibbs free energies of the two phases of the phase-change material are equal (see Figure 3-16), and

$$
\begin{gathered}
\Delta G=0=G_{\beta}-G_{\alpha}=H_{\beta}-H_{\alpha}-T_{t}\left(S_{\beta}-S_{\alpha}\right) \\
\Delta H=H_{\beta}-H_{\alpha}=T_{t}\left(S_{\beta}-S_{\alpha}\right)=T_{t} \Delta S
\end{gathered}
$$

where $G_{\alpha}, H_{\alpha}$, and $S_{\alpha}$ are the Gibbs free energy, enthalpy, and entropy of the low-temperature phase and the $S$ subscripted symbols have the same meaning for the high-temperature phase. A large enthalpy of transformation $\Delta H$ can occur only if there is a correspondingiy large increase in the entropy $\Delta S$.

If hydrogen bonding in the low-temperature phase of the phase-change material constrains the molecular noticn and these bonds are broken at the transition temperature, then the increased molecular freedom could account for the increased entropy of the higher temperature phase. The increase in enthalpy then wouid be closeiy related to the number and strength of hydrogen bonds in the low-temperature phase. 


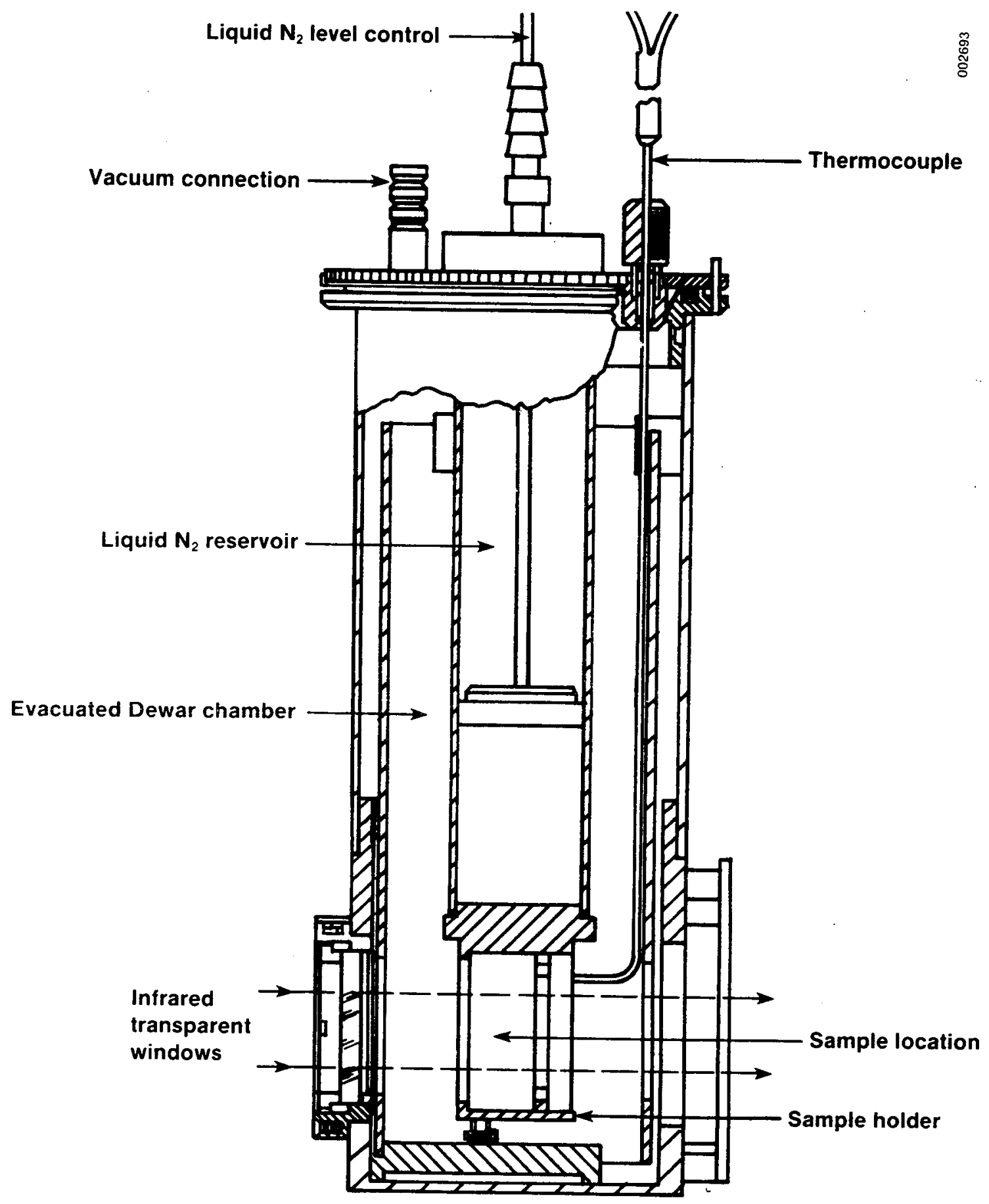

Figure 3-12. Cross Section of a Controlled Temperature Sample Holder for IR Spectroscopy of Solid-State Phase-Change Materials 


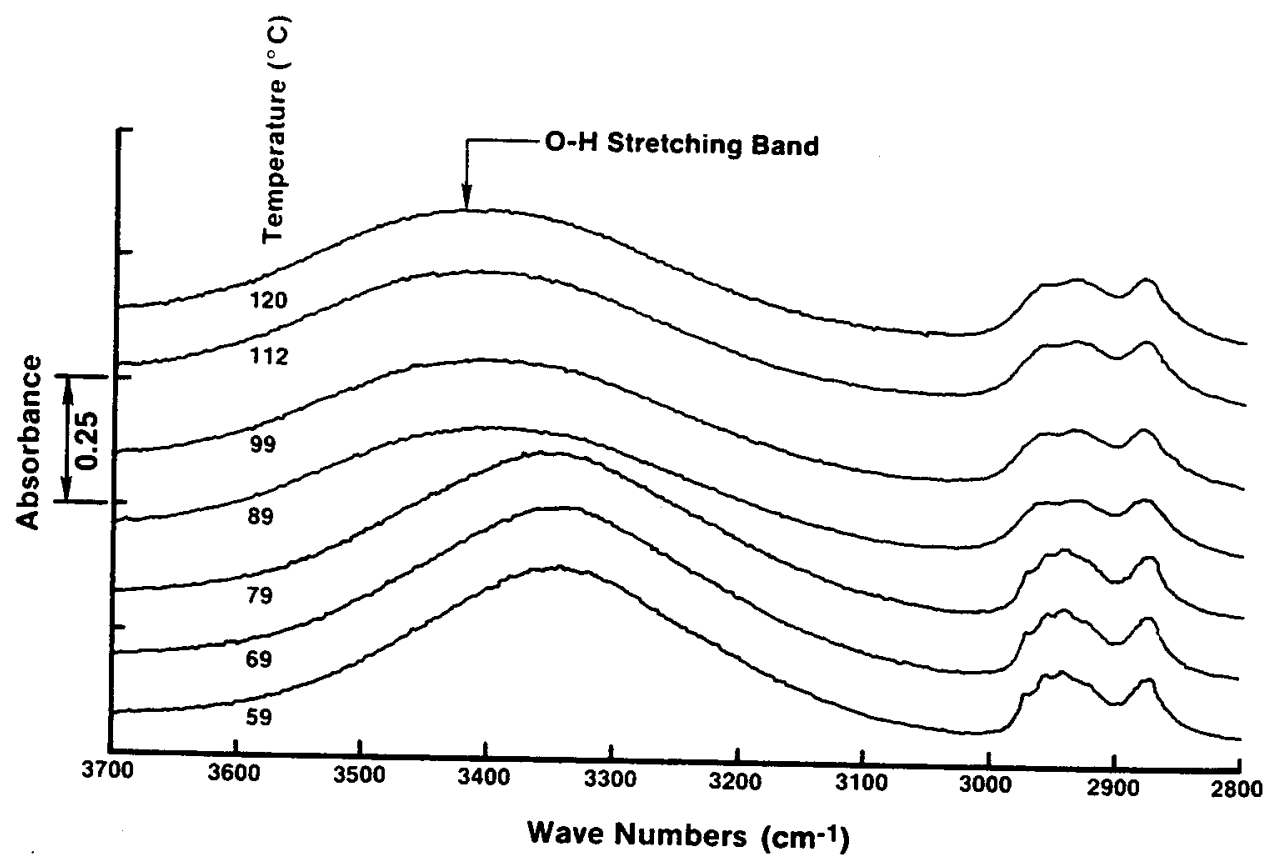

Figure 3-13. Infrared Absorbance Spectra of PG

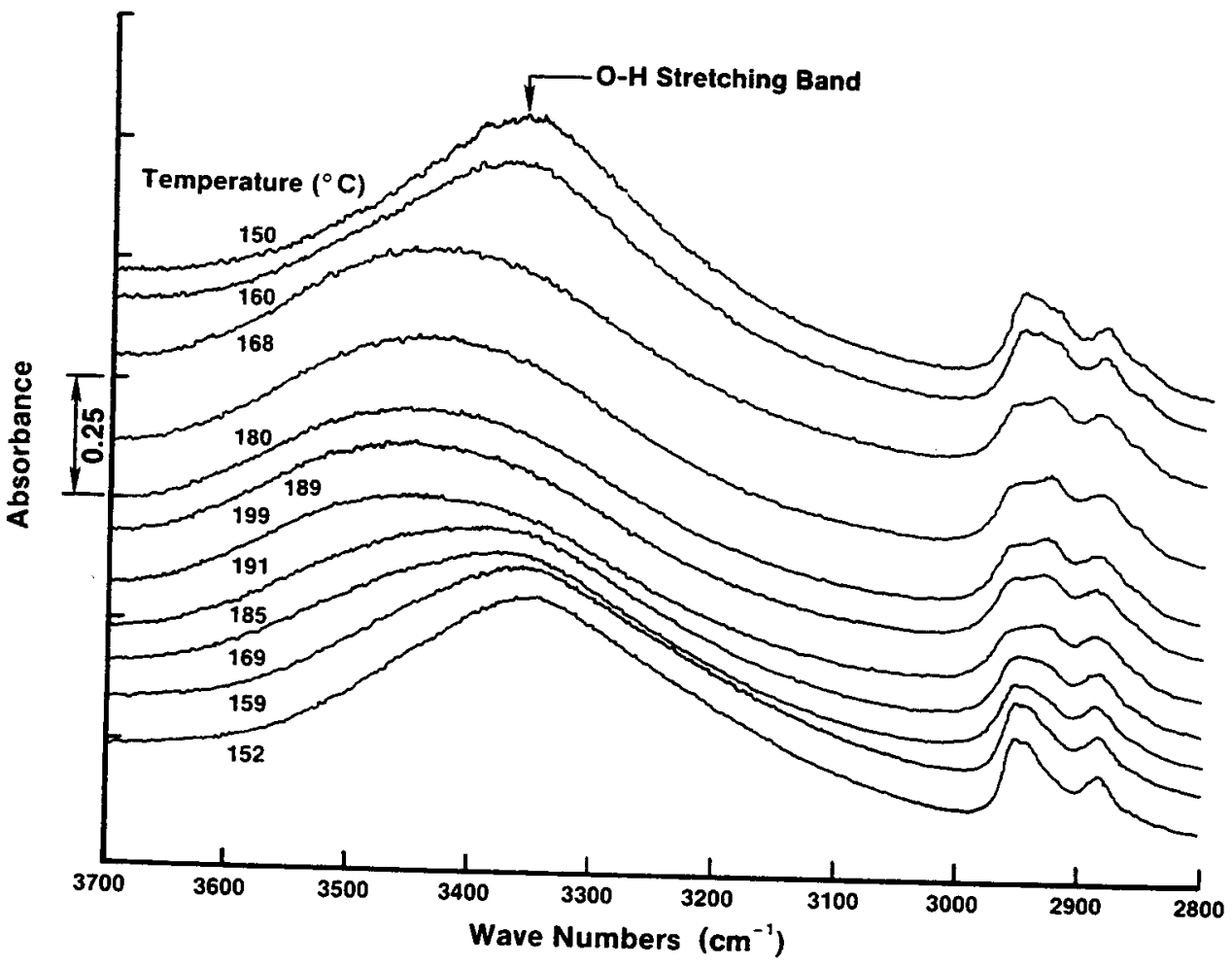

Figure 3-14. Infrared Absorbance Spectra of PE 


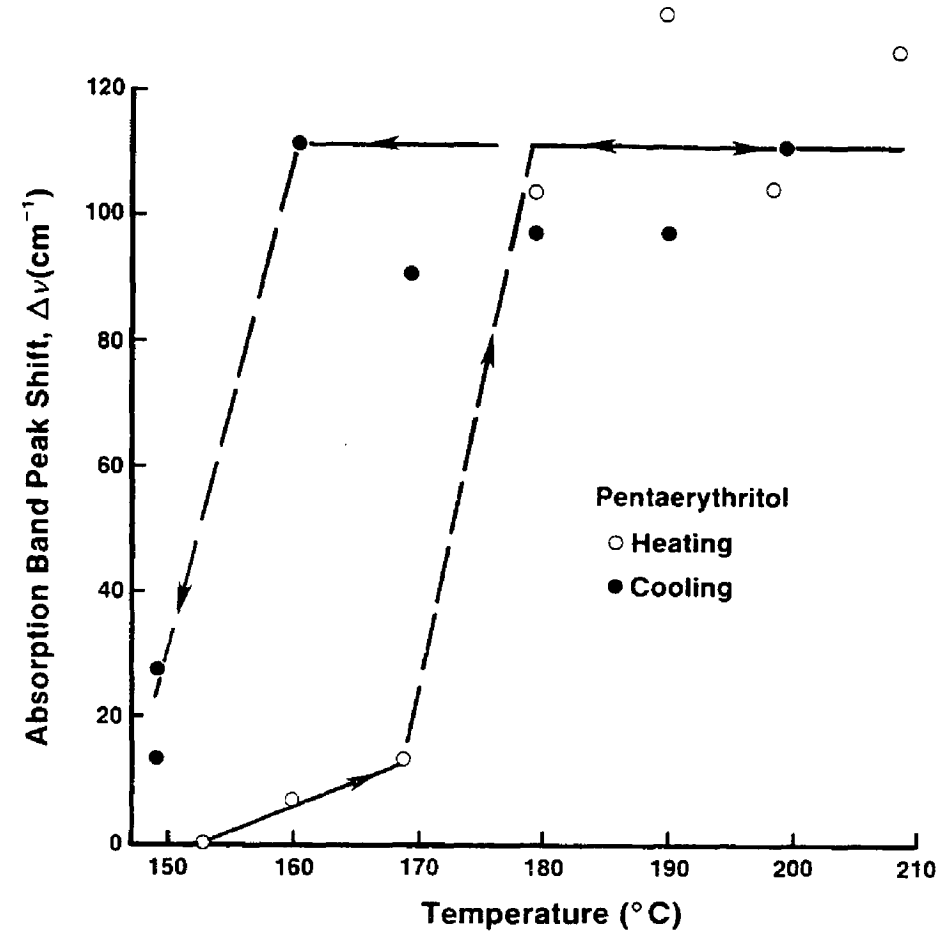

Figure 3-15. OH Absorption Band Peak Shift as a Function of Temperature in PE

Table 3-3. Hydroxyl Absorption Band Peak $\left(\mathrm{cm}^{-1}\right)$

\begin{tabular}{llll}
\multicolumn{1}{c}{ Alcohol } & Monomers & Dimers & Polymers \\
\hline $\mathrm{CH}_{3} \mathrm{OH}$ & 3642 & 3510 & 3340 \\
$\mathrm{C}_{2} \mathrm{H}_{5} \mathrm{OH}$ & 3632 & 3500 & 3330 \\
$\mathrm{C}_{6} \mathrm{H}_{5} \mathrm{CH}_{2} \mathrm{CH}\left(\mathrm{CH}_{3}\right) \mathrm{OH}$ & 3622 & 3480 & 3350 \\
$\mathrm{C}_{6} \mathrm{H}_{10} \mathrm{OH}$ & 3623 & 3480 & 3332 \\
\hline
\end{tabular}

Source: Ref. 13.

\subsection{A NEAREST-NEIGHBOR INTERACTION MODEL}

Infrared spectroscopy has provided evidence that hydrogen bonding may be involved in the solid-state transformation of PE, PG, and NPE. In particular, a reversible hydrogen bonding may occur between adjacent hydroxyl groups on neighboring molecules. The plausibility of this hypothesis was tested and found to be promising, as shown in the following discussion.

The homologs of $\mathrm{PE}$ all have tetrahedral molecules with from zero hydroxyl groups (neopentane, $\mathrm{C}_{5} \mathrm{H}_{12}$ ) to four hydroxyl groups ( $\mathrm{PE}, \mathrm{C}_{5} \mathrm{H}_{12} \mathrm{O}_{4}$ ) per 


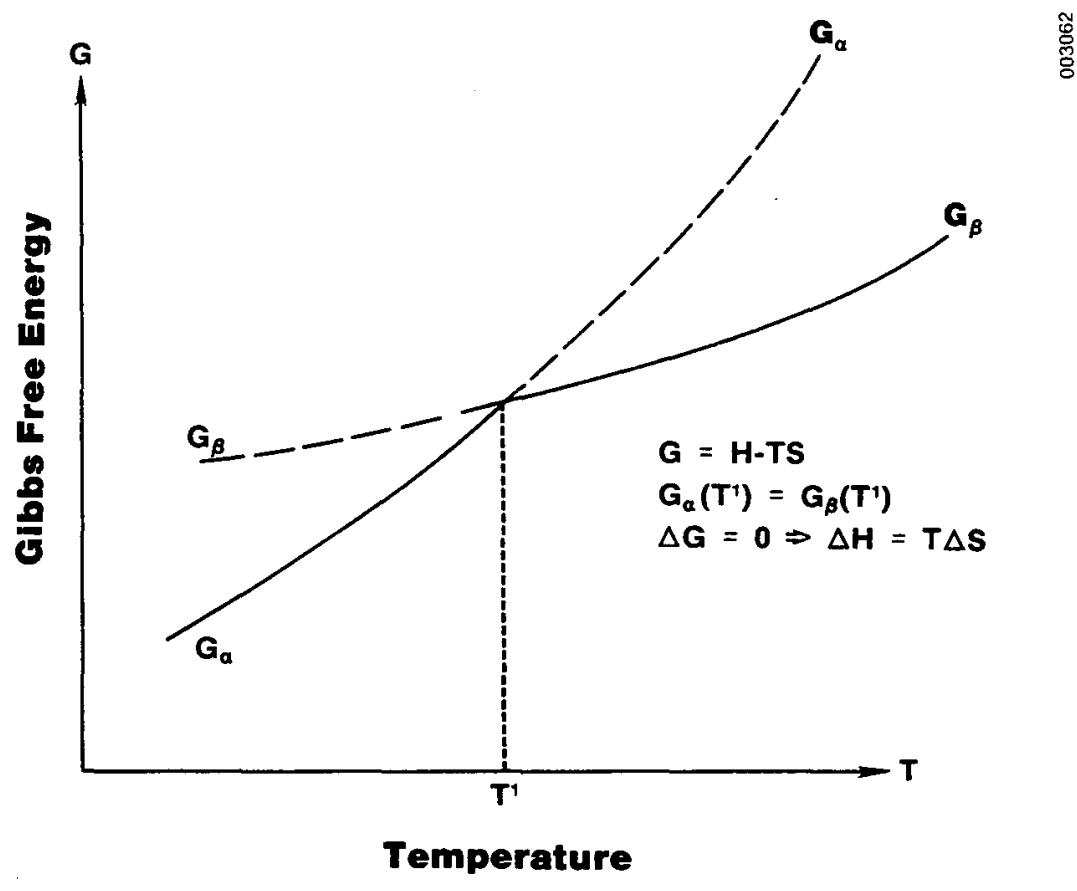

\section{Figure 3-16. Gibbs Free Energy vs. Temperature for a First-0rder Phase Change from $\alpha$ to $\beta$ at $T^{1}$}

molecule. If the nearest-neighbor interactions were dependent on interactions between hydroxyl groups, then the enthalpies of solid-state transformations should depend simply upon the probabilities of such groups existing in juxtaposition.

If $P G$, with only three hydroxyl groups, were in a cubic lattice, then the probability that a given hydroxyl group would be aligned with a nearestneighbor hydroxy 1 group would be $3 / 4$; the average number of hydrogen bonds per molecule would be

$$
\mathrm{N}_{3}=3 \times 3 / 4 \text {. }
$$

Similarly, for neopentyl-glycol with two hydroxyl groups, the average number of hydrogen bonds per molecule in the cubic lattice would be

$$
\mathrm{N}_{2}=2 \times 2 / 4 \text {. }
$$

For neopentyl alcohol with one hydroxyl group, the average number of bonds in the cubic lattice is

$$
\mathrm{N}_{1}=1 \times 1 / 4
$$

For neopentane with zero hydroxyl groups, the average number of bonds in the cubic lattice is

$$
\mathrm{N}_{0}=0 \times 0 / 4 \text {, }
$$


and in the same terms for pentaerythritol,

$$
\mathrm{N}_{4}=4 \times 4 / 4 \text {. }
$$

Generally, if $\mathrm{n}$ is the number of hydroxyl groups per molecule, then the average number of hydrogen bonds per molecule in the cubic phase is

$$
\mathrm{N}=\mathrm{n} \times \frac{\mathrm{n}}{4}=\frac{\mathrm{n}^{2}}{4}
$$

The number of such bonds remaining in the high-temperature phase remains an unknown $x_{n}$ for each of the compounds. However, the high-temperature infrared spectra show no evidence of residual, kydrogen bonded -OH groups. Therefore, we will assume for simplicity that the number of hydrogen bonds per molecule in the high-temperature phase is zero.

Now, if the enthalpy of transformation is primarily a result of hydrogen bond formation, for any of the pentaerythritol homologs:

$$
\Delta H \simeq E_{H}\left[N(n)-X_{n}\right]+\Delta H_{O},
$$

where the $\Delta \mathrm{H}_{\mathrm{O}}$ equals the nonhydrogen bond contributions and $\mathrm{E}_{\mathrm{H}}$ is the potential energy of a single hydrogen bond.

The magnitude of the nonhydrogen bond contribution is indicated by the enthalpy of transformation for neopentane, $\Delta \mathrm{H}_{\mathrm{o}}=2.6 \mathrm{~kJ} / \mathrm{mol}$, which has no hydroxyl groups. The bond strength $\mathrm{E}_{\mathrm{H}}$ can be estimated from the enthalpy of transformation of pentaerythritol $\triangle \mathrm{H}_{\mathrm{PE}}$ as follows:

$$
\mathrm{E}_{\mathrm{H}}=\frac{1}{4-\mathrm{X}_{4}}\left(\Delta \mathrm{H}_{\mathrm{PE}}-\Delta \mathrm{H}_{\mathrm{O}}\right) \text {, }
$$

and the enthalpies of transformation can be expressed as:

$$
\Delta H(n)=\Delta H_{0}+E_{H}\left[N(n)-X_{n}\right]=\Delta H_{0}+\frac{\left(\Delta H_{P E}-\Delta H_{0}\right)}{4-X_{4}}\left(\frac{n^{2}}{4}-X_{n}\right),
$$

and

$$
\Delta \mathrm{H}(\mathrm{n}) \simeq \Delta \mathrm{H}_{\mathrm{O}}+\frac{\mathrm{n}^{2}}{16}\left(\Delta \mathrm{H}_{\mathrm{PE}}-\Delta \mathrm{H}_{\mathrm{O}}\right),
$$

for $X=0$. This prediction was compared against the complete, consistent set of measurements on the pentaerythritol homologous series by Murrill and Breed [7].

Figure 3-17 shows the measured versus predicted values for $\Delta H(n)$. The predicted results amount to a two-point curve fjt to the $\mathrm{n}^{2}$ relationship of Eq. 3-24. Nevertheless, the agreement is sufficient to conclude that a nearest-neighbor interaction model for the solid-state transformation is plausible. 


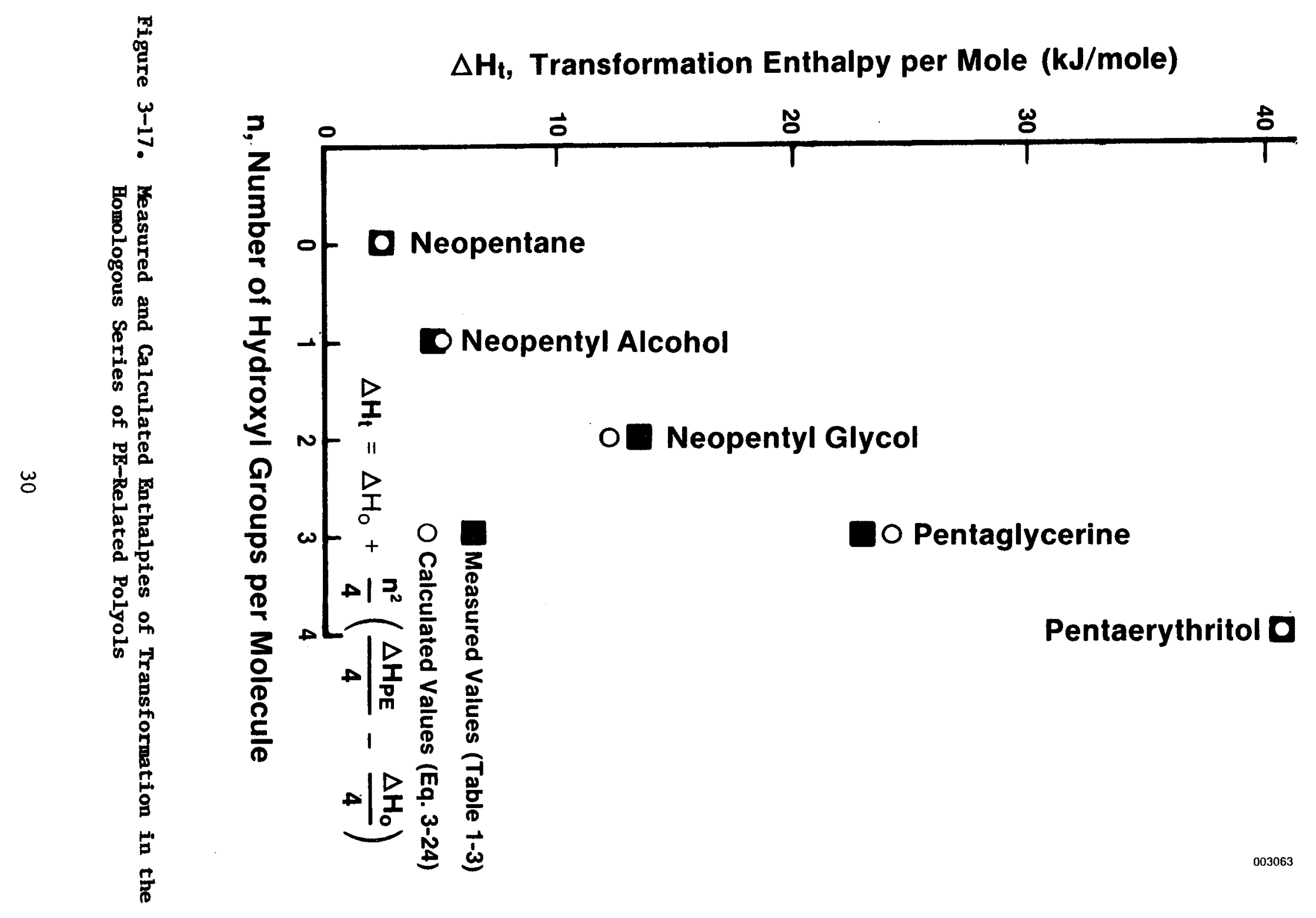




\subsection{SYSTEMS ANALYSES OF SOLID-STATE PHASE-CHANGE MATERIAL USE IN A TROMBE WALL}

\subsubsection{Computer Modeling of a Trombe Wall Performance}

A thermal network model was developed for the Trombe wall and was incorporated into a thermal simulation code for residential buildings. A SERI experimental house that has been subjected to extensive Class A monitoring was modeled using the SERIRES computer code $[14,15]$. The simulation is performed using forward finite differencing with time steps of one hour or less.

Table 3-4 lists the characteristics of the modeled house. A base building annual heating load of 11.7 million Btu $\left(12.3 \times 10^{9} \mathrm{~J}\right)$ was determined from a SERIRES simulation assuming an adiabatic south-facing wall (for the purpose of calculating solar savings fraction). The assumed characteristics of the Trombe wall are listed in Table 3-5. Thermal storage was modeled with multiple thermal nodes to account for the effect of thermal conductivity and the resulting temperature gradients in the wall. For the phase-change materials, this multinode modeling used the SERIRES code with multiple single-node phase-change material layers, each with a specific thermal conductivity. Simulation results showed hourly Trombe wall surface temperatures and heat fluxes on selected days. Annual solar savings fractions were based on annual simulations with and without the Trombe wall. As a check, the predicted performance of a concrete Trombe wall was compared to the performance predicted by a solar load ratio method developed at Los Alamos [16]. The two predictions agreed well.

Figure 3-18 shows the results of a series of simulations with solid-state phase-change temperature as a parameter. Assuming no supercooling, the optimum phase-change temperature is about $29^{\circ} \mathrm{C}\left(84^{\circ} \mathrm{F}\right)$. The inclusion of a supercooling effect of several degrees would yet be likely to raise this optimum temperature, but this possibility has not yet been simulated. Figure 3-19 also shows the incremental benefit of increasing the thermal conductivity of the phase-change material when the transition temperature is near optimum. Such an increase may be achieved by adding a material with a high thermal conductivity to the phase-change material. Figure 3-19 further displays the effect of thermal conductivity on the predicted performance of a solid-state phase-change material Trombe wall.

Finally, we compared the performance of a hypothetical solid-state phasechange material wall to a more conventional, concrete Trombe wall. Figure 3-20 shows that such a phase-change material wall might perform about as well as a much thicker concrete wall. If the thermal conductivity were increased, the phase-change material wall might perform significantly better than the concrete wall.

\subsubsection{Economic Feasibility}

It is not yet possible to design an optimized thermal energy storage system using solid-state phase-change materials. Much more information is needed about the materials themselves and about their performance as it is affected 
Table 3-4. Building Characteristics and Assumptions ${ }^{a}$

\begin{tabular}{|c|c|}
\hline Floor area & $=1080 \mathrm{ft}^{2}\left(100 \mathrm{~m}^{2}\right)$ \\
\hline Windows & $=$ double glazed \\
\hline Ceiling insulation & $\begin{array}{c}=R 30\left(\mathrm{ft}^{2} \mathrm{O}_{\mathrm{F}} \mathrm{h} / \mathrm{Btu}\right) \\
\left(\mathrm{k}=0.19 \mathrm{~W} / \mathrm{m}^{2} \mathrm{~K}\right)\end{array}$ \\
\hline Walls insulation & $=R 11(k=0.515)$ \\
\hline Crawl space walls & \\
\hline insulation & $=R 19(k=0.30)$ \\
\hline Infiltration & $=0.5$ air changes per hour \\
\hline Internal gains & $\begin{aligned}= & 53,000 \mathrm{Btu} / \text { day } \\
& (56 \mathrm{MJ} / \text { day })\end{aligned}$ \\
\hline Heating setpoint & $=68^{\circ} \mathrm{F}\left(20^{\circ} \mathrm{C}\right)$ \\
\hline Venting setpoint & $=76^{\circ} \mathrm{F} \quad\left(24.4^{\circ} \mathrm{C}\right)$ \\
\hline Cooling setpoint & $=78^{\circ} \mathrm{F} \quad\left(25.6^{\circ} \mathrm{C}\right)$ \\
\hline
\end{tabular}

${ }^{a}$ Retrofit Test House at SERI--Denver, CO (modeled as a single thermal zone).

Table 3-5. Trombe Wall Characteristics and Assumptions

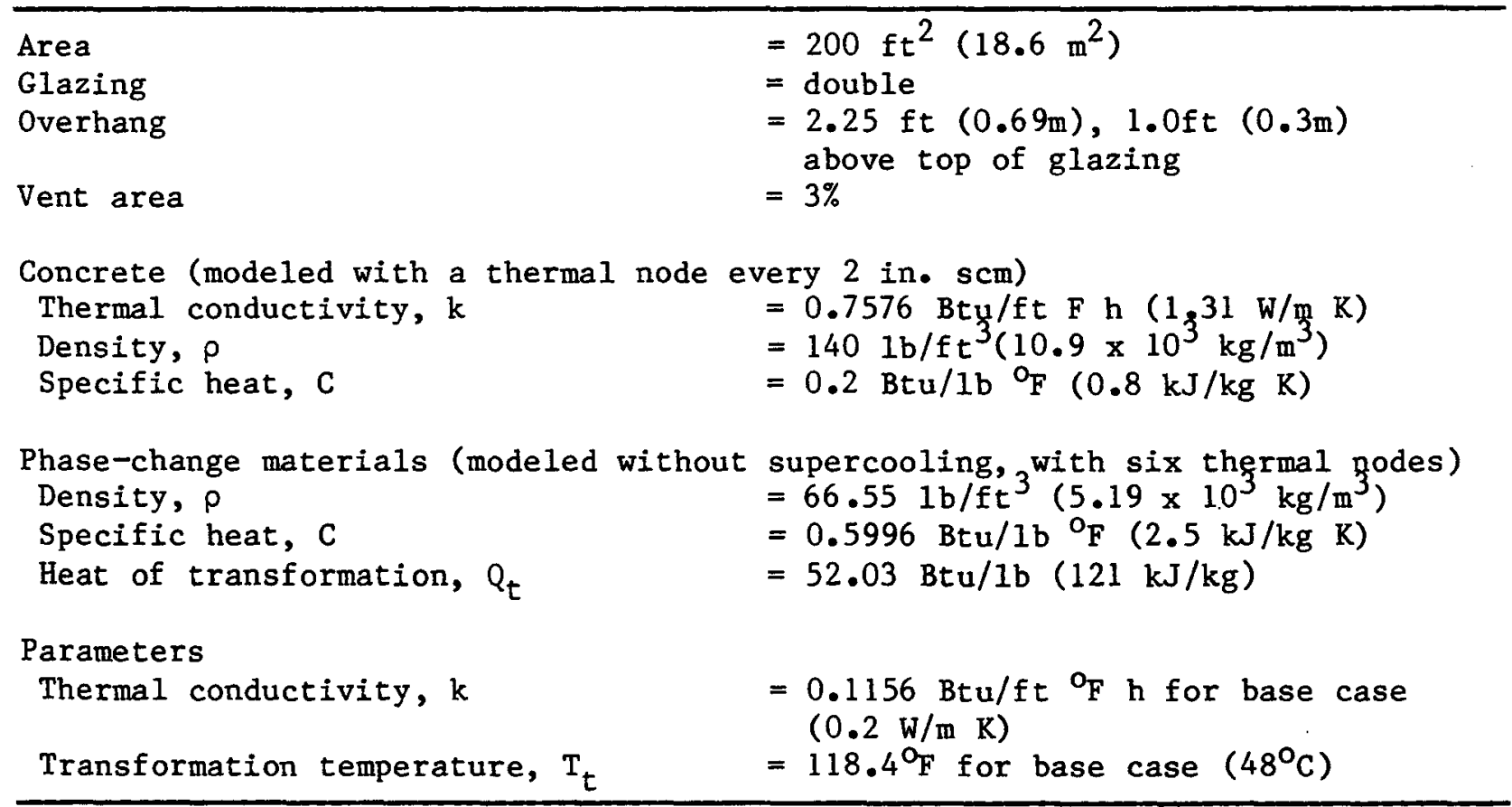




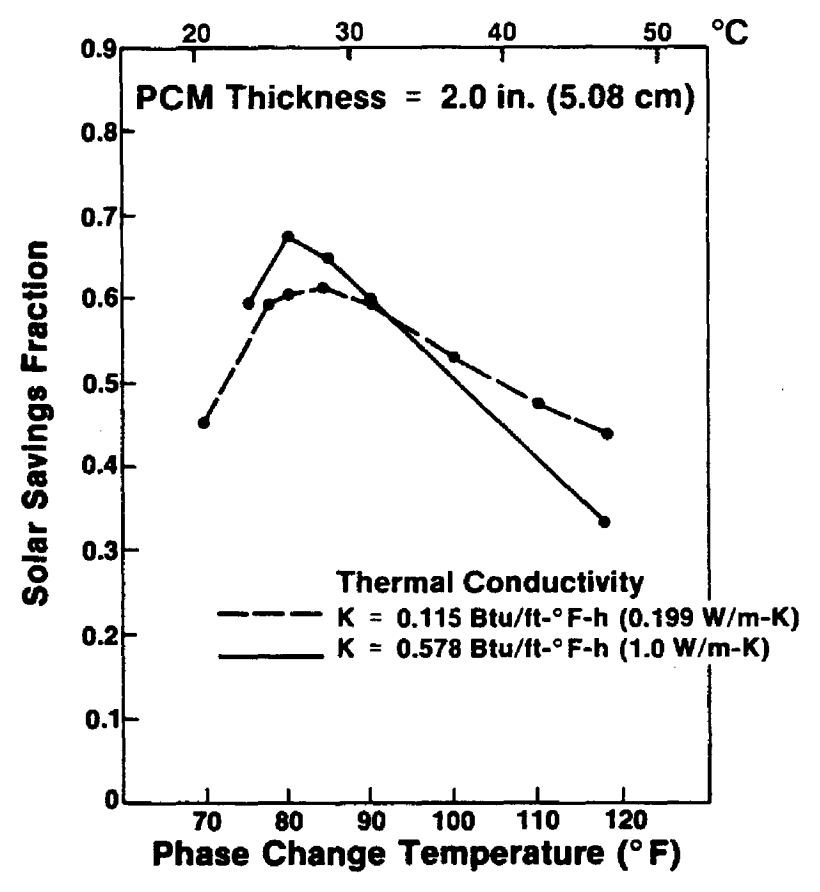

Figure 3-18. Solar Savings Fraction as a Function of the Solid-State Transformation Temperature in a Phase-Change Material-Pilled Trombe Wall

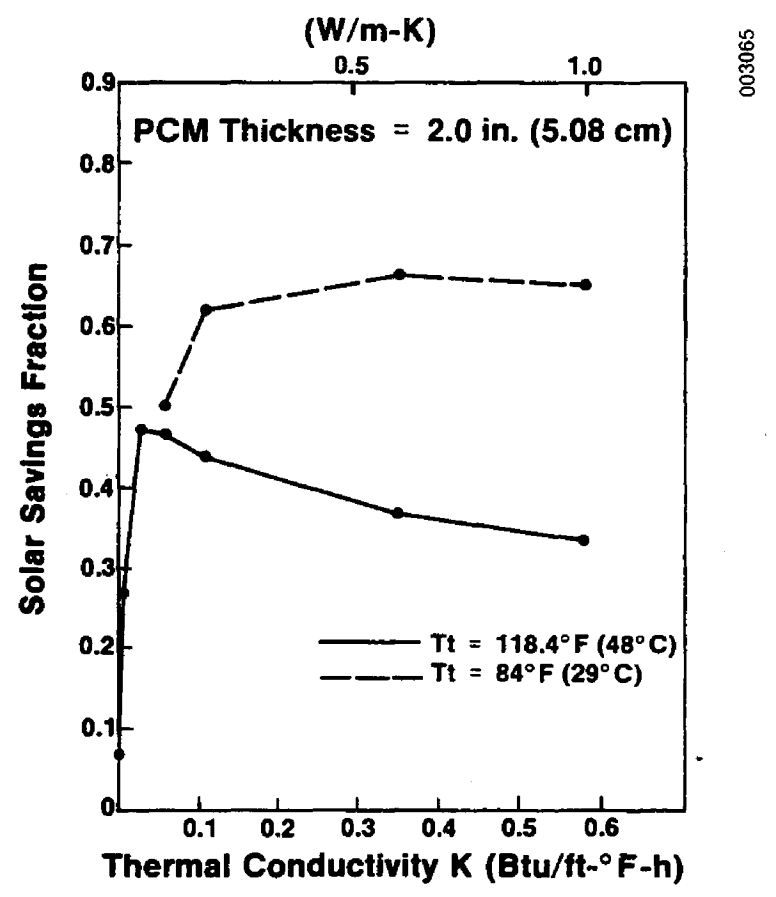

Figure 3-19. Solar Saving Fraction as a Function of Thermal Conductivity Assumed for a Solid-State Phase-Change Material 


\section{Concrete Thickness}

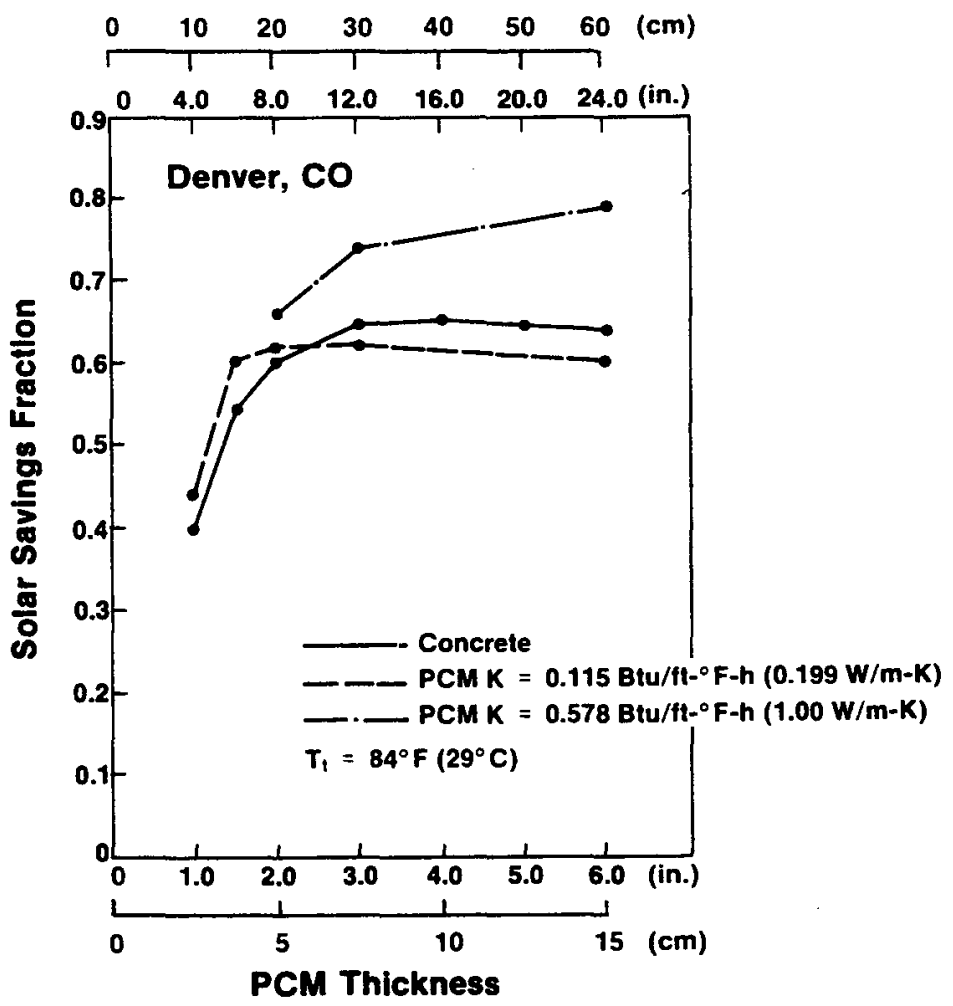

Figure 3-20. Solar Savings Fraction as a Function of Trombe Wall Thickness for Both Solid-State Phase-Change Materials and Concrete

by system design. At present, no engineering scale testing has been done, and all thermodynamic property data have been measured on very small samples. The kinetics of the solid-state transformation process, particularly the degree of undercooling, are expected to be dependent upon sample mass, purity, and the presence of other substances including additives to enhance thermal conductance and the container itself. For this reason no undercooling has been modeled, and only a very preliminary estimate of the cost effectiveness is presented at this time. Indeed, the best applications for these materials have not yet been determined. Nevertheless, it is instructive to compare the estimated costs of solid-state phase-change materials against the cost of conventional materials in the application that has been identified so far.

The computer simulations summarized in the previous section indicated that a 1.5-in. thick solid-state phase-change material wall would perform as well as an 8-in. $(0.2 \mathrm{~m})$ thick concrete Trombe wall. Each could provide about $60 \%$ annual fuel saving.

Table 3-6 lists the estimated costs of materials and labor for constructing a $200-\mathrm{ft}^{2}\left(18.6-\mathrm{m}^{2}\right)$ Trombe wall. The assumed cost of the phase-change material is $\$ 1 / 1 \mathrm{~b}(\$ 2.2 / \mathrm{kg})$, a figure that is about $40 \%-70 \%$ above the raw material cost and probably reasonable for a mass-produced item. Even though eight times as much concrete is required, the cost of the phase-change material still exceeds all of the materials costs in the concrete wall by $11 \%$. Assuming that the phase-change material wall can be constructed in the same manner as a wood 
Table 3-6. Rstimated Costs for Masonry and Phase-Change Material Trombe Walls ( $\$$ )

\begin{tabular}{|c|c|c|c|c|c|c|}
\hline \multirow{2}{*}{ Component } & \multicolumn{3}{|c|}{ Masonry ${ }^{a}$} & \multicolumn{3}{|c|}{ Solid-State Phase-Change Materials } \\
\hline & Materials & $\begin{array}{l}\text { Materials } \\
\text { Costs }\end{array}$ & $\begin{array}{l}\text { Labor } \\
\text { Costs }\end{array}$ & Materials & $\begin{array}{l}\text { Materials } \\
\text { Costs }\end{array}$ & $\begin{array}{l}\text { Labor } \\
\text { Costs }\end{array}$ \\
\hline $\begin{array}{l}\text { Storage } \\
\text { materia1 }\end{array}$ & $\begin{array}{l}200 \mathrm{ft}^{2}\left(18.6 \mathrm{~m}^{2}\right) \text { of } 8-\mathrm{in} . \\
(0.2-\mathrm{m}) \text { thick slump block } \\
(14,4001 \mathrm{~b}, 6545 \mathrm{~kg})\end{array}$ & 367 & & $\begin{array}{l}200 \mathrm{ft}^{2}\left(18.6 \mathrm{~m}^{2}\right) \text { of } 1-\mathrm{l} / 2-\mathrm{in} . \\
(3.8-\mathrm{cm}) \text { thick PCM }(18201 \mathrm{~b} \\
825 \mathrm{~kg}) \text { as composite wa11 } \\
\text { board }\end{array}$ & 1,820 & \\
\hline $\begin{array}{l}\text { Structural } \\
\text { support }\end{array}$ & $\begin{array}{l}\text { Masonry cement } \\
\text { Sand and mortar } \\
\text { Coloring } \\
\text { Concrete block fill } \\
\text { Concrete footings } \\
\text { Rebar and Durowa11 } \\
\text { reinforcing }\end{array}$ & $\begin{array}{l}78 \\
93 \\
73 \\
77\end{array}$ & 832 & $\begin{array}{l}\text { Typical of } 6-i n .(0.15-m) \text { frame } \\
\text { wall }\end{array}$ & 150 & 900 \\
\hline Glazing & $\begin{array}{l}\text { Wood frame for glazing } \\
\text { Glazing material }\end{array}$ & $\begin{array}{r}41 \\
558\end{array}$ & $\begin{array}{l}137 \\
200\end{array}$ & $\begin{array}{l}\text { Wood frame for glazing } \\
\text { Glazing material. }\end{array}$ & $\begin{array}{r}41 \\
558\end{array}$ & $\begin{array}{l}137 \\
200\end{array}$ \\
\hline \multirow[t]{5}{*}{ Misce 11 aneous } & $\begin{array}{l}\text { Stain } \\
\text { Ductwork }\end{array}$ & $\begin{array}{r}17 \\
325\end{array}$ & $\begin{array}{l}53 \\
63\end{array}$ & $\begin{array}{l}\text { Stain } \\
\text { Ductwork }\end{array}$ & $\begin{array}{r}17 \\
325\end{array}$ & $\begin{array}{l}53 \\
63\end{array}$ \\
\hline & & 1,629 & 1,285 & & 2,911 & 1,353 \\
\hline & TOTAL COST & \multicolumn{2}{|c|}{2,914} & & \multicolumn{2}{|c|}{4,264} \\
\hline & \multicolumn{3}{|c|}{$\begin{array}{l}\text { Less credit for } 6-\mathrm{in} .(0.15-\mathrm{m}) \\
\text { frame wall that would have } \\
\text { been required }\left(200 \mathrm{ft}^{2} \text { at }\right. \\
\left.\$ 5.25 / \mathrm{ft}^{2}\right)\end{array}$} & & \multicolumn{2}{|c|}{$-1,050$} \\
\hline & NET $\operatorname{cosT}$ & \multicolumn{2}{|c|}{1,864} & & \multicolumn{2}{|c|}{3,214} \\
\hline
\end{tabular}

adapted from Ref. 17 . 
frame wall, its labor costs are comparable to those required for the concrete wall. The other finishing costs, such as framing and glazing, would be identical. The total costs for these two Trombe walls differ by a factor of nearly 2.

These preliminary calculations indicate that major improvements in the performance of phase-change materials are necessary before they are likely to be economical for use in applications such as Trombe walls. These improvements may take two forms--an increase in the heat of transformation or an improved optimization of other properties for this application. For example, a measure of undercooling may be advantageous in Trombe walls. In that case, the increase in the optimum transition temperature (upon heating) would permit the use of solid-solution mixtures with greater latent heat of transformation. If a major increase in latent heat of transformation is needed at lower temperatures, and if it is physically possible, it is likely to be achieved only after the mechanism of the transformation is thoroughly understood. 


\section{SECTION 4.0}

\section{CONCLUSIONS AND RECOLRENDATIONS}

Solid-state phase-change materials based on pentaerythritol and its homologs can be mixed as binary solid solutions to produce phase-transformation temperatures of any desired value from below room temperature to $188^{\circ} \mathrm{C}$. Latent heats of transformation for these mixtures generally range from 84 to $293 \mathrm{~kJ} / \mathrm{kg}$. Limited experiments suggest that the solid-solution mixtures are stable and provide reproducible transformation characteristics for at least several hundred cycles.

The solid-state phase-change materials exhibit large degrees of undercooling; the degree depends on the exact composition and the heating and cooling rates used. The addition of particulate nucleating agents in the solid phase-change material has been shown to decrease the amount of undercooling to $10^{\circ} \mathrm{C}$. "The most effective nucleating agent identified so far is a finely powered graphite.

Computer simulations of a building's performance with an idealized (no undercooling), solid-state phase-change material Trombe wall suggests that the phase-change material wall could outperform a more conventional, concrete Trombe wall that was four times thicker and nine times heavier. Parametric studies showed that an optimum transformation temperature for the phase-change material wall was $29^{\circ} \mathrm{C}\left(84^{\circ} \mathrm{F}\right)$ and that improved performance resulted from increased phase-change material thermal conductivity (when zero supercooling is assumed).

Preliminary economic analyses suggest that solid-state phase-change materials may be too expensive to compete with concrete and other sensible heat storage materials in conventional Trombe wall designs. However, they may offer significant design advantages in applications where massive structures are impractical, such as retrofits to existing buildings and in modular passive solar buildings.

Research in two areas should improve the economic attractiveness of phasechange materials. Systems analyses should be extended to examine the effect of undercooling on Trombe wall performance, and models should be developed to predict the performance of these same materials in other passive solar applications (such as thermosyphon air panels and direct-gain walls and floors). Other applications not yet identified or more nearly optimized designs may use solid-state phase-change materials more effectively. Basic research on physical mechanisms should be extended because a better understanding of the phasechange process could lead to significant improvements in the performance of these materials. 
SECTION 5.0

\section{REFERENCES}

1. Anon., Chemical Marketing Reporter, Vol. 223, No. 7, Feb. 14, 1983, Schnell Publishing Co., New York, New York.

2. Hale, D. V., M. J. Hoover, and M. J. O'Neill, Phase-Change Materials Handbook, NASA Report MFS-22064, Aug. 1972. Available from NTIS.

3. Murrill, E., and L. Breed, "Solid-Solid Phase Transitions Determined by Differential Scanning Calorimetry, Part I, Tetrahedral Substances," Thermochimica Acta, Vol. 1, 1970, p. 239-46.

4. Murrill, E., and L. Breed, "Solid-Solid Phase Transitions Determined by Differential Scanning Calorimetry, Part II, Octahedral Substances," Thermochimica Acta, Vol. 1, 1970, p. 409-14.

5. Murrill, E., and L. Breed, "Solid-Solid Phase Transitions Determined by Differential Scanning Calorimetry, Part III, Organosilicon Compounds," Inorganic Chemistry, Vo1. 10, No. 3, 1971, pp. 641-3.

6. Murril1, E., and L. Breed, "Solid-Solid Phase Transitions Determined by Differential Scanning Calorimetry, Part IV, New Transitions in Tetrahedral Substances," Thermochemica Acta, Vol. 3, 1972, pp. 311-5.

7. Murrill, E., and L. Breed, "Space Thermal Control by Use of Solid/Solid Phase Change Materials," Annual Summary Report No. 1, NASA Contract No. NAS 8-21452, July 1969 .

8. Brennan, W. P., Theory and Practice of Thermoanalytical Calorimetry, Ph. D. Thesis, Princeton, NJ: Princton University, 1971. Available through University Microfilms No. 71-25,930.

9. Garn, P. D., and 0. Menis, "ICTA Certified Reference Materials for Differential Thermal Analysis, Differential Scanning Calorimetry, and Related Techniques from $125-940^{\circ} \mathrm{C}, "$ available from the National Bureau of Standards, Washington, D.C., Office of Standard Reference Materials.

10. Cali, J. P. Certificate of Standard Reference Material 720, Synthetic Sapphire $\left(\mathrm{Al}_{2} \mathrm{O}_{3}\right)$, Washington, DC: National Bureau of Standards, Office of Standard Reference Materials, Aug. 1970.

11. Thomas, J. M., and T. A. Clark, "Evaluation of Kinetic Parameters from Thermoanalytical Techniques, Dehydration of Manganous Formate Dihydrate," J. Chem. Soc. (A), 1968, p. 457 .

12. Analytical Accessories, Ltd.

Unit 3, Lagoon Road, St. Mary Cray

Orpington, Kent, BR5 3QX, Great Britain 
13. Luck, W. A. P., "Angle Dependence of Hydrogen Bands," The Hydrogen Bond II: Structure and Spectroscopy, edited by P. Schuster et al., Amsterdam: North-Holland Publishing Co., 1976.

14. Palmiter, L. and T. Wheeling, "SERIRES Version 1.0 User's Manual," (to be available from NTIS).

15. Wortman, D. and J. Burch, Empirical Validation Using Class A Data, SERI/TR-254-1840, forthcoming.

16. Balcomb, J. D., et al., Passive Solar Design Handbook, Vo1. II, DOE/CS-0127/2, Jan. 1980 .

17. Ward, D., et al. Solar Heating and Cooling of Buildings, Sizing, Installation and Operations of Systems," Washington, DC: U.S. Department of Commerce, 1980, p. 3-31. Available from the U.S. Government Printing office.

18. Salyer, I. O., et al., "Form-Stable Crystalline Polymer Pellets for Thermal-Energy Storage," Proceedings of the Intersociety Energy Conversion Engineering Conference, San Diego, CA, Aug. 1978.

19. Busico, V., et al., "Solid-Solid Phase Transitions for Thermal Energy Storage," Thermal Storage of Solar Energy, edited by C. den Ouden, Boston: TNO and Martinus Nijhoff, 1981, p. 309-327.

20. Swet, C. J., "Phase-Change Storage in Passive Solar Architecture," Proceedings of the Fifth National Passive Solar Conference, Amherst, MA, 19-26 Oct. 1980, pp. 282-286.

21. Lane, G. A., and P. J. Moses, "Cool Storage Phase Change Materials for Off-Peak Electric Power," Proceedings of the Thermal Energy Storage Workshop, Palo A1to, CA: Electric Power Research Institute, forthcoming. Held on 17-20 Jan. 1983. 


\section{APPENDIX \\ TOXICITY OF PENTAERYTHRITOL, PENTAGLYCERINE, AND NEOPENTYL-GLYCOL}

The three compounds pentaerythritol ( $P E)$, pentaglycerine ( $P G$ ), and neopentylglycol (NPG) are produced in large quantities for use in the manufacture of resin paints, lubricants, inks, detergents, explosives, plastics, and other products. A systematic search of the literature was conducted, and the limited information about the toxicity of these compounds is summarized in this section.

PE and PG are classified as nontoxic by conventional industrial hygiene standards. NPG is considered slightly toxic. However, as is true of most chemicals, large doses of these compounds can be harmful, and chronic exposure may cause medical problems that are not anticipated by short-term tests on animals. The toxicity of PE and NPG have been thoroughly studied. We found very little information about the toxicity of PG.

$\mathrm{PE}$ is considered nontoxic under U.S. Department of Labor standards [1]. Very large doses can cause the death of laboratory animals by severe dehydration. Smaller doses cause diarrhea. Rats fed a diet containing 5\% (by dry weight) of $\mathrm{PE}$ over a three-month period developed severe diarrhea but no other direct effects. Laboratory tests with animals have defined the acute oral doses required to cause death (Table $A-1)[2,3]$.

$\mathrm{PE}$ was slightly irritating to the eyes of rabbits, but the irritation cleared within 24 hours of exposure. Rats, dogs, and guinea pigs exposed to PE dust $\left(8 \mathrm{~g} / \mathrm{m}^{3}\right.$ of air) for 6 hours per day for 90 days showed no adverse effects $[1,3]$.

Table A-1. Lethal Dosage Levels of Pentaerythritol for Laboratory Animals (Acute Oral Toxicity Results)

\begin{tabular}{lc}
\hline \multicolumn{1}{c}{ Animal } & $\begin{array}{c}\text { Lethal Dose }\left(\mathrm{LD}_{50}{ }^{\mathrm{a}}\right) \\
(\mathrm{g} / \mathrm{g} \text { of body weight })\end{array}$ \\
\hline Guinea pig & 0.0113 \\
Rat & $<0.016$ \\
Mouse & 0.0255 \\
\hline
\end{tabular}

Source: Ref. 3.
$\mathrm{a}_{\mathrm{LD}}{ }_{50 \text { is the median lethal dose }}$
statistically estimated to be
sufficient to kill $50 \%$ of the
laboratory animal test population [2].


Experiments on humans have shown that $80 \%$ of ingested $\mathrm{PE}$ is eliminated in the urine within 30 hours without alteration. While the PE is in the human system, it causes an increase in blood sugar concentration but no other adverse effects [2].

NPG is slightly toxic in animal tests. Rats fed diets containing $1.0 \%$ and $0.1 \%$ (by dry weight) of NPG over a period of 36 days showed a slight reduction in weight gain and food intake only for the larger dose and no other clinical effects. In general, NPG is rapidly eliminated in the urine.

High concentrations of NPG vapors are toxic to laboratory animals. Rats exposed to vapors at a high concentration ( 4 wt \% of NPG in air) for 6 hours/day for 10 days suffered diarrhea and weight loss, and one of the three exposed rats died. Rats exposed to $0.4 \mathrm{wt} \%$ of NPG vapors for 6 hours/day for 10 days showed signs of irritation but continued to gain weight normally during the test period. Acute lethal dose levels are summarized in Table A-2.

NPG applied to the skin of guinea pigs causes slight irritation, but the chemical is not absorbed into the tissue. Manufacturers' experience has shown that human skin is also irritated by NPG and peeling can occur in some cases.

Tests have shown that NPG is irritating to the eyes of rabbits, and the manufacturers' experience indicates that the vapors can cause irritation of eyes, noses, and throats of humans [4].

PG is considered to be nonhazardous by U.S. Department of Labor standards. PG is only slightly irritating when applied to the abraded skin of a rabbit and is nonirritating when applied to the eyes of a rabbit. The acute lethal dosage of $\mathrm{PG}\left(L D_{50}\right)$ is greater than $0.005 \mathrm{gram} / \mathrm{gram}$ body weight either by oral or injected routes when administered to laboratory mice $[1,3]$.

Table A-2. Lethal Dosage Levels of Neopenty1-G1ycol for Laboratory Animals

\begin{tabular}{lc}
\hline \multicolumn{1}{c}{ Animal } & $\begin{array}{c}\text { Lethal Dose } \mathrm{LD}_{50} \\
(\mathrm{~g} / \mathrm{g} \text { of body weight }\end{array}$ \\
\hline Acute Oral Toxicity Results $[2,5]$ & 0.0032 \\
Guinea pig & $0.0032-0.0064$ \\
Mouse &. \\
Acute Injected Toxicity Results & \\
\hline Rats and mice & $0.016-0.032$ \\
\hline $\begin{array}{l}\text { a Dose injected directly into the membrane lining of the } \\
\text { abdominal cavity. }\end{array}$
\end{tabular}




\section{REFERENCES}

1. U.S. Department of Labor, Bureau of Labor Standards, "Mineral Data Safety Sheet of Pentaerythritol, Pentaglycerine and Neopentyl-Glycol," form number LSB-005-4.

2. Kirk-0thmer, Encyclopedia of Chemical Technology, 3rd Edition, John Wiley \& Sons Inc., 1978.

3. International Minerals and Chemical Corporation, "A Complete Guide," Des Plaines, IL.

4. Eastman Chemicals, "Technical Data Publication," No. N-154C, May 1981.

5. Sax, N. Irving, Dangerous Properties of Industrial Materials, 5th Edition; Litton Educational Publishing, Inc., 1979, pp. 271-279, 848, 889.

6. The Merck Index, Ninth Edition, Merck and Co., Inc., 1976.

7. "American Industrial Hygiene Association," Hygienic Guide Series, p. 101-102, Jan.-Feb. 1968.

8. Hercules Coatings Service Laboratory, CSL-214A, Hercules Incorporated, Wilmington, DE. 


\section{PASSIVE heATINg AND COOLING PROGRAM DISTRIBUTION LIST}

DOE

Mr. James Binkley

Department of Energy

Route CE-111, Room GF-253

Forrestal Building

1000 Independence Ave., SW

Washington, DC 20585

Mr. Jean Boulin

Department of Energy

Route CE-111, Room GF-253

Forrestal Building

1000 Independence Ave., SW

Washington, DC 20585

Ms. Rebecca Dyer

Department of Energy

Route CE-111, Room GF-253

Forrestal Building

1000 Independence Ave., SW

Washington, DC 20585

Mr. Robert Holliday

Department of Energy

Route CE-111, Room GF-253

Forrestal Building

1000 Independence Ave., SW

Washington, DC 20585

Ms - Mary Margaret Jenior

Department of Energy

Route CE-111, Room GF-253

Forrestal Building

1000 Independence Ave., SW

Washington, DC 20585

Mr. Ted Kurkowski

Department of Energy

Route CE-111, Room GF-253

Forrestal Building

1000 Independence Ave., SW

Washington, DC 20585

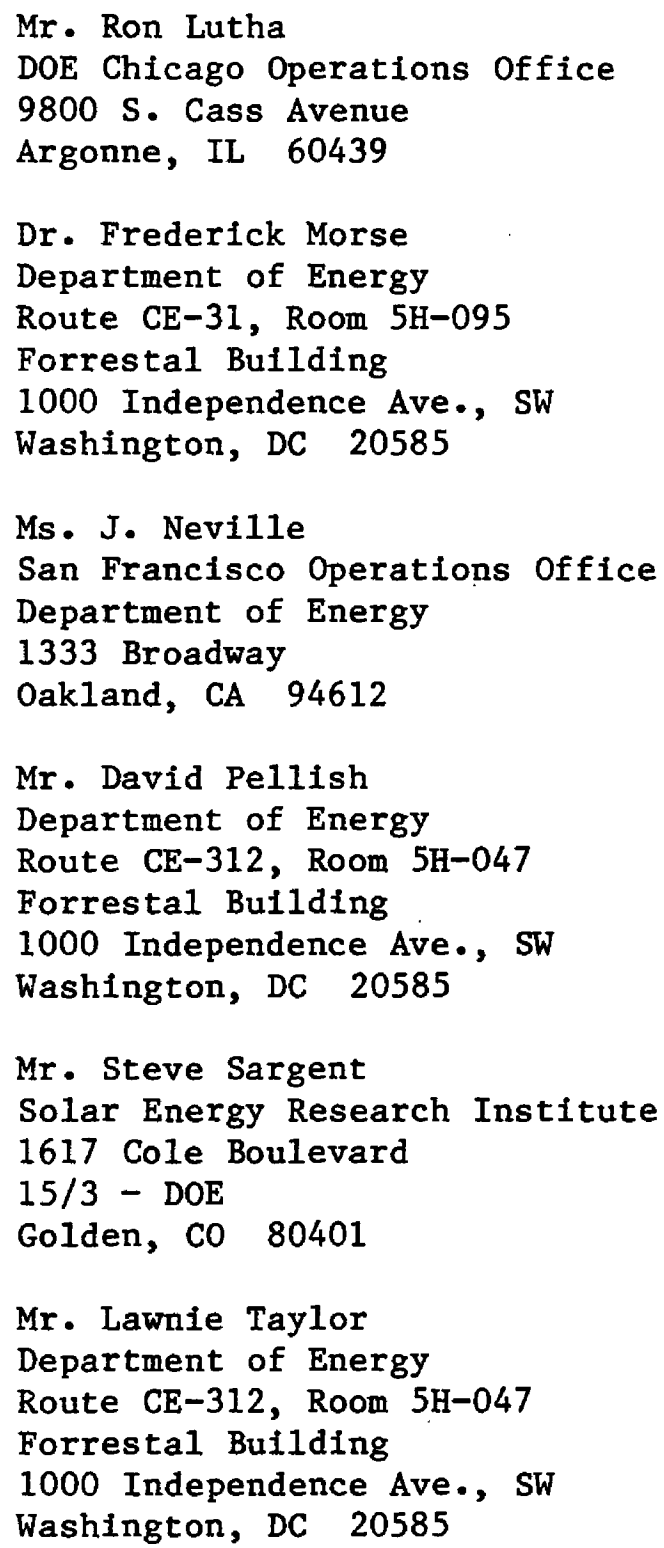


Mr. Keith Davidson

Gas Research Institute

8600 W. Bryn Mawr Avenue

Chicago, IL 60631

Mr. William Whiddon

Whiddon \& Assoc.

4330 East-West Highway

Suite 914

Bethesda, MD 20814

Mr. Bill Wright

15 Blueberry Lane

Lexington, MA 02173

Mr. Dave Benson

SERI

1617 Cole BIvd.

Floor $16 / 3$

Golden, CO 80401

Mr. Craig Christensen

SERI

1617 Cole Blvd.

F1oor $15 / 3$

Golden, CO 80401

Mr. Robert Dikkers

National Bureau of Standards

Building 226, Room B-320

Gaithersburg, MD 20899

Mr. Larry Flowers

SERI

1617 Cole Blvd.

Floor $15 / 3$

Golden, CO 80401

Dr. Bob Jones

Los Alamos National Lab

P.0. Box 1663, Mail Stop K577

Los Alamos, NM 87545

Dr. Ron Kammerud

Lawrence Berkeley Lab

One Cyclotron Road

Berkeley, CA 94720

Mr. Michael McCabe

National Bureau of Standards

Building 226, Room A 319

Washington, DC 20234
Mr. Claude Robbins

SERI

1617 Cole Blvd.

Floor $15 / 3$

Golden, C̣O 80401

Mr. Steve Selkowitz

Lawrence Berkeley Lab

One Cyclotron Road

Building 90, Room 3111

Berkeley, CA 94720

Mr. John Tomlinson

Oak Ridge National Laboratory

Box Y, Building 9204-1

Oak Ridge, TN 37830

Mr. Thomas Bligh

Massachusetts Inst. of Technology

Room 3-457

Cambridge, MA 02139

Dr. Subrato Chandra

Florida Solar Energy Center

300 State Road, 401

Cape Canaveral, FL 32920

Mr. Claridge

Colorado University

Boulder, CO 80302

Mr. Gene Clark

Trinity University

Solar Data Center

San Antonio, TX 78284

Dr. John Duffie

University of Wisconsin-Madison

1500 Johnson Drive

Madison, WI 53706

Dr. Bruce Hunn

University of Texas at Austin

Building 143

Austin, TX 78712

Mr. Ron Goldner

Tufts University

Medford, MA 02155

Mr. S. Mahajan

California State University

Sacramento, CA 95819 
Mr. George Meixel

University of Minnesota

Minneapolis, MN 55455

Dr. I. Salyer

University of Dayton

Research Institute

300 College Park

Dayton, OH 45469

Dr. Byron Winn

Colorado State University

Dept. of Mechanical Engineering

Fort Collins, CO 80523

Dr. James Pearson

John Brown University

Dept. of Electrical Engineering

Siloam Springs, AR 72761

Mr. Mike Bell

National Association of

Home Builders

15 th and $M$ Streets, NW

Washington, DC 20006

Mr. Bion Howard

National Concrete Masonry Assoc.

Box 781

Herndon, VA 22070

Mr. Ralph Johnson

NAHB Research Foundation, Inc.

3720 T. Street, NW

Washington, DC 20007

Mr. Earl Kennett

American Institute of Architects

1735 New York Avenue, NW

Washington, DC 20006

Mr. Jim Leech

500 Northstar Court

Boulder, CO 80302

Mr. William Seaton

ASHRAE

1791 Tullie Circle, NE

Atlanta, GA 30329

Mr. Chuck Bankston

2861 Arizona Terrace, NW

Washington, DC 20016
Mr. Herman Barkman

107 Cienega Street

Santa Fe, NM 87501

Mr. Richard L. Crowther

Crowther Solar Group

410 A Madison Street

Denver, CO 80206

Mr. Deane M. Evans, Jr. Steven Winter Associates, Inc. 6100 Empire State Building

N.Y., NY 10001

Mr. Michael Holtz

Architectural Energy Consultants.

3600 E. Virginia Avenue

Denver, CO 80209

Mr. Victor Sedrick

Kalwall Corporation

P.0. Box 237

Manchester, NH 03105

Dr. Robert Imes

Celanese Chemical Co., Inc.

86 Morris Avenue

Summit, NJ 07901

Mr. John Goglick

Eastman Chemical Products, Inc.

Kingsport, TN 37662

Mr. David Holzman

Solar Age Magazine

1719 Lamont Street, NW

Washington, DC 20010

Mr. Timothy Maloney

One Design, Inc.

Mountain Falls Road

Winchester, VA 22601

Mr. Paul Moses

Dow Chemical Co.

Larkin Laboratory

Midland, MI 48640

Mr. C. J. Swet

7040 Woodville Road

Mt. Airy, MD 21771 
Dr. Daniel O'Neil

Georgia Tech Research Inst.

Energy and Materials Sciences Lab

Atlanta, GA 30332

Ms. Anne Gumerlock

Berkeley Solar Group

P.0. Box 3289

Berkeley, CA 94703

Ms. Veronica Rabl

Energy Management \& Utilization Div.

Electric Power Research Institute

3412 Hillview Avenue

Palo Alto, CA 94304 


\begin{tabular}{|c|c|c|}
\hline $\begin{array}{l}\text { Document Control } \\
\text { Page }\end{array}$ & $\begin{array}{l}\text { 1. SERI Report No. } \\
\text { SERI/TR-255-1828 }\end{array}$ & 3. Recipient's Accession No. \\
\hline \multirow{2}{*}{\multicolumn{2}{|c|}{$\begin{array}{l}\text { 4. Title and Subtitle } \\
\text { Materials Research for Passive Solar Systems: } \\
\text { Solid-State Phase-Change Materials }\end{array}$}} & $\begin{array}{l}\text { 5. Publication Date } \\
\text { March } 1985\end{array}$ \\
\hline & & 6. \\
\hline $\begin{array}{ll}\text { 7. Author(s) } & \text { D. K. B B } \\
\text { J. D. M }\end{array}$ & $\begin{array}{l}\text { nson, J. D. Webb, R. W. Burrows, } \\
\text { Fadden, C. Christensen }\end{array}$ & 8. Performing Organization Rept. No. \\
\hline \multirow{2}{*}{\multicolumn{2}{|c|}{$\begin{array}{l}\text { 9. Performing Organization Name and Address } \\
\text { Solar Energy Research Institute } \\
1617 \text { Cole Boulevard } \\
\text { Golden, Colorado } 80401\end{array}$}} & $\begin{array}{l}\text { 10. Project/Task/Work Unit No. } \\
1275.00 \text { and } 1464.00\end{array}$ \\
\hline & & $\begin{array}{l}\text { 11. Contract (C) or Grant (G) No. } \\
\text { (C) } \\
\text { (G) }\end{array}$ \\
\hline \multirow{2}{*}{\multicolumn{2}{|c|}{ 2. Sponsoring Organization Name and Address }} & $\begin{array}{l}\text { 13. Type of Report \& Period Covered } \\
\text { Technical Report }\end{array}$ \\
\hline & & 14. \\
\hline
\end{tabular}

15. Supplementary Notes

6. Abstract (Limit: 200 words) A set of soljd-state phase-change materjals is being evaluated for possible use in passive solar thermal energy storage systems. The most promising materials are organic solid solutions of pentaerythritol $\left(\mathrm{C}_{5} \mathrm{H}_{12} \mathrm{O}_{4}\right)$, pentaglycerine $\left(\mathrm{C}_{5} \mathrm{H}_{12} \mathrm{O}_{3}\right)$, and neopentyl glycol $\left(\mathrm{C}_{5} \mathrm{H}_{12} \mathrm{O}_{2}\right)$. Solid solution mixtures of these compounds can be tailored so that they exhibit solid-to-solid phase transformations at any desired temperature between $25^{\circ} \mathrm{C}$ and $188^{\circ} \mathrm{C}$, and have latent heats of transformation between 20 and $70 \mathrm{cal} / \mathrm{g}$. Transformation temperatures, specific heats, and latent heats of transformation have been measured for a number of these materials. Limited cyclic experiments suggest that the solid solutions are stable. These phase-change materials exhibit large amounts of undercooling; however, the addition of certain nucleating agents as particulate dispersions in the solid phase-change material greatly reduces this effect. Computer simulations suggest that the use of an optimized solid-state phase-change material in a Trombe wall could provide better performance than a concrete Trombe wall four times thicker and nine times heavier. Nevertheless, a higher cost of the phase-change materials ( $\cong 0.70$ per pound) is 1 ikely to Timit their applicability in passive solar systems unless their performance can be significantly improved through further research.

17. Document Analysis

a. Descriptors Calorimetry; Computerized simulations; Nucleation; Passive solar heating systems; Phase-change materials; Phase transformations; Thermodynamic properties; Toxicity; Spectroscopy

b. Identifiers/Open-Ended Terms Infrared spectroscopy; Neopentyl-glycol; Pentaerythritol; Pentaglycerine; Solid-to-solid phase-change materials

c. UC Categories

Availability Statement

National Technical Information Service

U.S. Department of Commerce

5285 Port Royal Road

Springfield, Virginia 22161

19. No. of Pages

\begin{tabular}{|l|}
\hline \\
58 \\
\hline 20. Price $\mathrm{AO4}$ \\
\end{tabular}

